\title{
Sobre la posibilidad de una teoría crítica*
}

\author{
György Márkus
}

$\mathrm{L}$ os comentarios esquemáticos precedentes sobre algunos de los intentos teóricos contemporáneos por sustituir o complementar el paradigma marxiano de la producción por otro paradigma (el de la comunicación $)^{1}$ tenían un solo propósito: señalar un motivo teórico mínimo por el cual el intento de radicalizar el paradigma marxiano de la producción, a pesar de sus múltiples insuficiencias y dificultades intrínsecas, deba emprenderse al menos como una de las alternativas del pensamiento radical contemporáneo. La discusión que

\footnotetext{
${ }^{1}$ Márkus se refiere al capítulo 4 denominado "Producción versus comunicación: cambio de paradigma en la teoría radical”, en el cual primero examina y critica brevemente el enfoque desarrollado por Jean Baudrillard, para analizar después, más detenidamente, el proyecto teórico de Jürgen Habermas que busca, a través del paradigma del lenguaje, complementar (y no sustituir como Baudrillard) el paradigma de la producción. Véase el resumen de estos análisis en la presentación de este ensayo. [Nota de Julio Boltvinik.]
}

sigue sólo puede proponerse indicar algunos de los problemas y de las consecuencias generales que tal intento debe enfrentar.

Ya habrá quedado claro el carácter general de la revisión sugerida. Consiste en proponer que las distinciones analíticas básicas mediante las cuales el paradigma marxiano se articula (la dicotomía "contenido material/forma social", "fuerzas productivas/relaciones de producción") se tomen como distinciones práctico-históricas en un sentido radical. Esto es, admitir que estas distinciones han de ser siempre relativas a algún proyecto histórico-social, en el fondo a la condición vital práctica, a las necesidades e intereses de agentes sociales concretos e históricamente particulares.

El paradigma de la producción implica una interpretación de la intersubjetividad como objetividad social que 'determina' a los individuos desde 'afuera', por lo menos en el sentido de que provee el material a partir

GYÖRGY MÁRKUS: Profesor emérito de filosofía de la Universidad de Sydney, Australia. george.markus@arts.usyd.edu.au

Traducción del inglés: Tessa Brisac. Revisión: Julio Boltvinik.

Desacatos, núm. 23, enero-abril 2007, pp. 179-200.

* Se trata del capítulo 5 de la parte II "Sobre el paradigma de la producción. El materialismo marxista y el problema de la constitución del mundo social”, del libro de György Márkus, Language and Production. A Critique of the Paradigms, D. Reidel Publishing Company, Dordrecht, Países Bajos, 1986, 190 pp. 


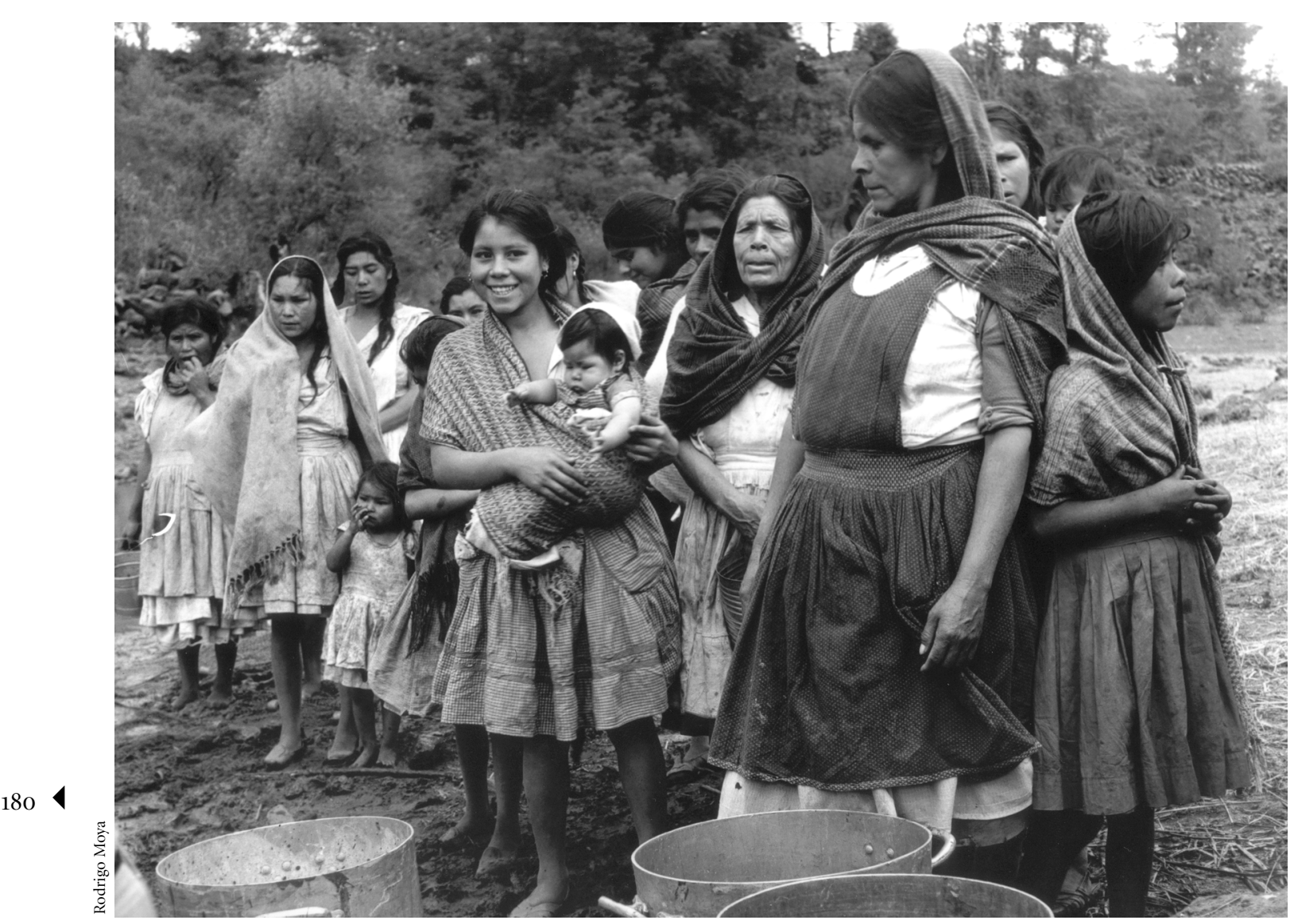

Mujeres tarascas, Opopeo, Michoacán, 1968.

del cual se construye - mediante el proceso social de "adquisición" e interiorización - toda personalidad concreta. Bajo esta luz, cada elemento humanamente significativo del entorno social no sólo es un 'producto' común de la naturaleza y del trabajo sino que representa, en el contexto de su uso, dentro del marco de la vida humana real, una coalescencia indisoluble de una realidad material-natural desnuda con alguna relación socialmente postulada y regulada de los sujetos activos con aquella realidad y entre ellos. Es una factualidad que, por su naturaleza misma, funciona también como el 'portador' de reglas y normas de varios tipos. Por el otro lado, las relaciones sociales entre sujetos humanos sólo son posibles a través de la mediación (directa o indirecta) de tal mundo de objetividad social. Así que, en el entorno social real, en el mundo vital inmediato de los individuos, cada hecho es —en el sentido anterior - institucional'. La ciencia natural como empresa cognitiva representa un intento de 'desantropomorfización', de alcanzar los 'hechos desnudos' de manera independiente tanto del entorno institucional de las sociedades humanas y de las limitaciones y determinaciones antropológicas de los organismos humanos. Pero esta empresa (a su vez histórica, 'instituida' y regulada mediante normas y procedimientos sociales cambiantes) no sólo es, en principio, interminable (ya que las ciencias naturales nunca pueden desatar el lazo que las conecta con el mundo vital de la objetividad social; esta conexión sólo puede volverse cada vez más lejana y controlada, pero siempre será epistemológicamente constitutiva para ellas), sino que implica también, y al 
mismo tiempo, la disolución progresiva de todas las relaciones sensoriales entre los 'hechos' y las acciones humanas. En la medida en que la distinción entre lo inevitable 'exterior' (al cual los individuos se tienen que adaptar) y lo inevitable generado por los mismos hombres (y que su actividad histórica colectiva puede 'deshacer') se debe establecer en relación con las propias acciones de los hombres, dentro del mundo social vital de los individuos, es imposible trazarla a menos que los individuos involucrados hagan un esfuerzo práctico para discernir hasta qué punto su propia actividad debe ser 'reproductiva' y en qué medida puede ser 'creativa.' Y aquí, 'debe' y 'puede' cobran sentido sólo en relación con lo que la terminología racionalista denomina 'voluntad' y 'decisión', pero que, de manera más realista, podemos llamar las exigencias e impulsos históricamente formados, las necesidades de los individuos concretos, de sus grupos y colectividades. La distinción aparentemente ontológica entre physis y nomos en el mundo, que está ahí para ser encontrada y descubierta por la 'razón', depende de una distinción práctica entre physis y poiesis en las actividades humanas, distinción que sólo los actores mismos pueden hacer. Esta distinción, sin embargo, tiene que hacerse si las actividades sociales creadoras de historia e históricamente creativas han de ser no sólo descritas con una terminología racionalista, sino que estas actividades realmente han de ser racionales, el resultado de la decisión consciente de los individuos involucrados. Porque no puede haber razón práctica (colectiva o individual) si no se distingue entre las condiciones y los objetivos de la actividad, de tal forma que en primera instancia se puedan plantear preguntas sobre la compatibilidad de los fines, su relación con los medios, sus consecuencias previsibles, etcétera.

Formuladas con tal generalidad filosófica, estas observaciones podrían ser consideradas como un rechazo puramente verbal de la 'teleología' marxiana y como la propuesta de un relativismo y un decisionismo extremos. Pero, en primer lugar, bien podrían parecer irrelevantes ya que las categorías marxianas no fueron concebidas para dar una interpretación filosófica de la vida humana. Fueron pensadas para constituir el andamiaje conceptual de una nueva 'ciencia concreta' de la historia y de la sociedad, ciencia que al mismo tiempo ayude a sus destinatarios a lograr una conciencia revolucionaria, al conformar tanto una expresión de sus intereses como una guía para su actividad colectiva radical. Las categorías analíticas del 'paradigma de la producción' sólo se pueden discutir de manera significativa si uno toma en cuenta este uso y este papel en la teoría marxiana en su conjunto. Para este fin, hace falta mirar un poco más de cerca la función teórica y práctica que cumple la dicotomía fuerzas productivas/relaciones de producción dentro de la totalidad del proyecto de Marx.

Como intenté demostrarlo anteriormente ${ }^{2}$, esta dicotomía cumple un doble papel: sirve, por un lado, para distinguir en la historia los ejes de continuidad y de discontinuidad, $\mathrm{y}$, al mismo tiempo, para trazar la frontera entre las condiciones básicas (objetivas y subjetivas) del cambio histórico y el terreno en el cual pueden ocurrir transformaciones sociales radicales y hacia el cual debería enfocarse la acción colectiva revolucionaria. Esto significa que mediante la ayuda de estas categorías, la historia es entendida como un progreso antinómico, fundamentalmente como la acumulación y la universalización, bajo una forma objetivada y alienada, de necesidades y capacidades sociales. Esto, a su vez, permite descubrir el lugar que ocupan los conflictos del presente en el conjunto del desarrollo humano, evaluar las confrontadas tendencias sociales desde el punto de vista de un sistema de 'valores' radicalmente histórico, de creación humana pero para nosotros, individuos contemporáneos, objetiva y universalmente válido. Por el otro lado, las mismas categorías permiten entender el presente no como una aglomeración momentánea de hechos accidentales sino como un sistema relativamente estable de relaciones que garantizan la reproducción de sus 'portadores': tanto de sus elementos materiales como de sus agentes humanos en su función y forma sociales determinadas. La dialéctica de las fuerzas productivas y las relaciones de producción conecta orgánicamente estos dos aspectos del análisis, el

\footnotetext{
2 Esta dicotomía es el tema central de la parte II de Language and Production, aunque en distintos capítulos se maneja de diversas maneras. Quizás la expresión más clara sea la que se presenta en las últimas páginas del capítulo 3 . Véase al respecto la síntesis incluida en la presentación de este ensayo. [Nota de Julio Boltvinik.]
} 
diacrónico y el sincrónico. Presenta un análisis del proceso de reproducción social desde el punto de vista de sus disfunciones y antinomias sistémicas, es decir, un análisis referido a sus posibilidades históricas dinámicas.

Cada uno de los elementos de este proyecto requiere ser examinado.

Las categorías de objetivación y de apropiación caracterizan el proceso histórico como un proceso de transmisión ininterrumpida de la tradición mediante actividades humanas práctico-materiales. Por medio de este proceso, los 'productos' de una generación anterior son nuevamente re-transformados en necesidades y capacidades subjetivas, cuyo ejercicio desemboca entonces en una 'reproducción' (pero nunca en una réplica) o en un cambio de este mundo que es la objetivación de "las fuerzas esenciales del hombre". La continuidad es por lo tanto una característica constitutiva de la historia humana, pues 'el hombre es el mundo de los hombres'. Incluso los intentos más radicales de una futura reorganización de la sociedad derivan, inevitablemente, de su organización y sus antinomias presentes. Las categorías de fuerzas protinuidad histórica como un proceso dialéctico y contradictorio de progreso, en el sentido de la universalización de las capacidades, necesidades, formas de relaciones y sistemas conceptuales de los seres humanos. Este progreso, para Marx, no puede reducirse al solo desarrollo de las fuerzas productivas (aunque se entienda éste en el amplio sentido 'antropológico' de una constante expansión de la esfera de la interacción de los seres humanos con la naturaleza y del correspondiente crecimiento del control consciente sobre este proceso metabólico). Pero las fuerzas productivas forman el esqueleto de la evolución histórica, en el sentido de que sólo respecto a ellas es que el progreso adquiere la forma de la acumulación, de un crecimiento y una expansión de los resultados ya alcanzados del desarrollo humano. Las fuerzas productivas son aquellos 'frutos de civilización' a los cuales 'el hombre nunca renuncia', como afirma Marx en su carta a Annenkov. Puesto que un nivel dado de desarrollo de las fuerzas productivas, 'heredado' por cada generación en una forma objetivada, circunscribe un campo definido de posibilidades, respecto tanto a la extensión como al carácter

de las relaciones sociales mediante las cuales pueden aquéllas ser reproducidas, los 'medios de producción' son, en este sentido, la 'vara de medición (Gradmesser) del desarrollo' que puede ser definido, entonces, con el rigor de una ciencia natural. Así, el paradigma de la producción establece una conexión supuestamente empírica entre la idea teórica (que es lógicamente necesaria dentro de su estructura) de la continuidad histórica y la idea, claramente valorativa, de progreso. La teoría basada en este paradigma se vuelve, por lo tanto, en su propio entendimiento, "la ciencia real, positiva... del proceso práctico del desarrollo humano"3.

Esta construcción es, sin embargo, altamente problemática por varias razones. El problema principal, desde nuestra perspectiva, se relaciona con la noción de acumulación que en Marx está profundamente impregnada de imaginación biológica ${ }^{4}$. La afirmación según la cual los hombres, por lo menos en su relación activa con la naturaleza, nunca renuncian a los frutos de la civilización, si se entiende (como parece que lo entendía el propio Marx) como una generalización empírica, es claramente falsa. Si acaso puede ser interpretada como un "postulado de racionalidad práctica", pero aun en este caso resultaría contrapuesta a los análisis que el propio Marx ofrece de las formaciones socio-económicas como unidades relativamente estables y discontinuas de progreso histórico. En este sentido hay una tensión latente entre la concepción marxiana de la diacronía y la de la sincronía.

\footnotetext{
${ }^{3}$ Marx-Engels Werke, vol. 3, Dietz, Berlín, 1958, p. 27. [No hay traducción al español de esta magna colección que reúne las obras completas de Marx y Engels.]

${ }^{4}$ Véase, por ejemplo, la caracterización marxiana del "desarrollo del trabajo" en las Teorien über den Merwert [en español: Teorías sobre la plusvalía, Fondo de Cultura Económica, México, 1980, 3 vols.]: “De la misma manera, Darwin hace de la 'acumulación' de rasgos heredados el principio conductor de la formación de todos los organismos, plantas y animales, de tal manera que los diversos órganos se forman por 'adición' y son meramente 'invenciones' de los sujetos vivos gradualmente acumuladas" (Werke, vol. 26/3, p. 289). La misma analogía reaparece en El capital, vol. 1 (Werke, vol. 23, p. 392). También llama la atención lo mucho que Marx, en El capital, incluso en su análisis de la revolución tecnológica, insiste en este aspecto de continuidad orgánica (cfr. ibid., pp 392-394, 404, etc.).
} 
En sus análisis comparativos de las formaciones socioeconómicas, Marx nunca cesó de subrayar que cada sistema de relaciones de producción (o más ampliamente: de relaciones sociales en general) definía y circunscribía un objetivo de producción (Zweck der Produktion) históricamente específico en el sentido de una funciónobjetivo socioeconómica que incluye la determinación objetiva de lo que, bajo las condiciones existentes, contará como insumo y como producto, es decir, como costo social y económicamente significativo y como resultado final útil. Esta idea, si bien se insiste poco en ella ${ }^{5}$, es una de las más fructíferas de Marx, ya que dota de unidad teórica sus múltiples observaciones relativas a las diferencias en la dirección del desarrollo de la producción bajo condiciones históricas cambiantes. Pero esto conlleva de inmediato que lo que es objetivamente una 'mejora', un 'progreso' de las fuerzas productivas bajo un conjunto dado de relaciones de producción pueda aparecer como una 'regresión' desde el punto de vista de otra sociedad (lo cual explica la necesidad de nociones como 'sobreadaptación', 'involución', 'decadencia', en todas las teorías 'evolucionistas' de la historia, incluida la historia de la tecnología) y, por lo tanto, implica que sí es posible que se 'renuncie' a este 'progreso' en la práctica, si se realizara una verdadera transición histórica hacia otro tipo de formación socioeconómica. El progreso del cultivo de arroz hidropónico en Asia del sureste implicó una 'regresión' del uso del arado al del azadón, y las admirables tecnologías semiartísticas del periodo manufacturero temprano se perdieron con la aparición de un desarrollo industrial capitalista. Diferentes sistemas de producción implican diferentes relaciones activas del hombre con la naturaleza, como el propio Marx lo demostró claramente en el caso del capitalismo, y esto también significa que requieren del cultivo y ejercicio de diferentes capacidades humanas en el sentido antropológico. El intento marxiano de en-

\footnotetext{
${ }^{5}$ Entre las pocas excepciones, véase la discusión de este concepto en G. Therborn, Science, Class and Society, Londres, 1976, pp. 385-386, además del artículo de J. Arnason ya mencionado. [N. de la T.: debe ser el que cita en la nota 107: J. Arnason, "Marx und Habermas", en A. Honneth y U. Jaeggi (eds.), Arbeit, Handlung, Normativität, Frankfurt, 1980.]
}

contrar en la noción de 'productividad' un criterio empírico neutral, que permita establecer un balance estricto de esas 'ganancias' y 'pérdidas', es sin duda fallido: no hay manera de dar a esta noción un sentido no ambiguo al aplicarla a sociedades en las cuales la fuerza de trabajo no se puede mover libremente entre varias ramas o segmentos de la 'economía', es decir, que el criterio no se aplica de manera coherente a las sociedades precapitalistas ${ }^{6}$. O bien uno identifica 'las fuerzas productivas' con alguna noción empírica preestablecida de técnica y tecnología - y en este caso hay que enfrentar el hecho de que, en tiempos de grandes transformaciones históricas, fuerzas productivas adquiridas pueden ser, hasta cierto punto, 'objeto de renuncia y abandono' (lo cual implica renunciar al vínculo entre su desarrollo y la noción de continuidad histórica, un vínculo constitutivo de todo el paradigma marxiano). O bien, la noción misma de fuerzas productivas ha de definirse a través de la continuidad histórica. Es decir, hay que definirlas como aquellos elementos subjetivos y objetivos de la riqueza social a cuyo uso productivo los individuos sociales (en un momento histórico dado) no 'renuncian', ni podrían hacerlo, ya que estos elementos o el producto de su utilización constituyen para ellos una precondición necesaria de la vida, al menos mientras no poseen o no generan alternativas reales para su sustitución? 7 .

\footnotetext{
${ }^{6}$ En primer lugar hay que señalar que, aplicada a la agricultura (es decir, a la rama de producción determinante en todas las economías precapitalistas), la noción de productividad se vuelve intrínsecamente ambigua por la necesidad de distinguir entre productividad por hora-hombre y por unidad de tierra. Éste, sin embargo, no es sólo un problema analítico: los dos tipos históricos fundamentales de ecosistemas agrícolas no europeos, la agricultura de tumba, roza y quema y la hidráulica (inundación o riego), muestran dos tendencias de desarrollo completamente opuestas respecto a estas dos maneras posibles de entender el crecimiento de la productividad agrícola. El cultivo eurasiático de granos, como ecotipo específico, es el único que hace históricamente posible un "crecimiento de la productividad agrícola" relativamente equilibrado y simultáneo en los dos aspectos. Véase al respecto, en primer lugar, Clifford Geertz, Agricultural Involution, University of California Press, Berkeley, 1963; también Eric R. Wolf, Peasants, Prentice-Hall, Englewood Cliffs, New Jersey, 1966, cap. 2; y Esther Boserup, The Conditions of Agricultural Growth, Aldine, Chicago, 1965, esp. cap. 2-5.

${ }^{7}$ Las "fuerzas productivas", en este sentido, comprenden tanto los conocimientos y las capacidades humanas (incluyendo formas definidas de capacidades y conocimientos organizacionales) como los "corres-
} 
Las fuerzas productivas son, en este sentido, lo que tiene, para la sociedad considerada, el significado de 'técnico' (los elementos de la vida social no investidos de valor y que constituyen el prius de la existencia humana). Pero esto implica también que los elementos objetivos o subjetivos que en una determinada sociedad funcionan como sus 'fuerzas productivas' pueden, en otra sociedad u otro periodo histórico, alcanzar objetivamente la función y el significado de 'relaciones de producción' o de sus 'materializaciones.' Ciertos medios de tecnología 'militar' son para algunas sociedades (por ejemplo, algunos pastores nómadas) medios de producción cuya reproducción requiere de expediciones sistemáticas de guerra y saqueo. Formas de saber que son estrictamente técnicas en cierto momento histórico pueden convertirse en formas de poder monopolizado si la sociedad en cuestión adquiere la posibilidad de reemplazarlas por otras formas mejor adaptadas a las necesidades de sus miembros ( por ejemplo, el 'saber' de los expertos reemplazado por el de los productores). Eso significa también que en una sociedad en la cual fuerzas sociales opuestas luchan por alternativas sociales distintas que corresponden a sus intereses y necesidades estructurales, la lucha ideológica se articula parcialmente en torno a la pregunta: ¿cuáles son las precondiciones 'técnicas' necesarias de la vida y cuáles son aquellas 'condiciones sociales' a las que tiene sentido cuestionar y tratar de cambiar? Desde el punto de vista de una economía política marxista, el mercado es un tipo definido de relación de producción institucionalizada; para la economía neoclásica es una precondición indis-

pondientes" medios de producción. Por el otro lado, la caracterización arriba presentada implica que las categorías de "fuerzas productivas/ relaciones de producción" se definen prima facie en relación con sociedades dinámicas en las cuales las cuestiones de cambio social consciente y de alternativas de desarrollo histórico se vuelven cuestiones sociales reales. En este sentido, el materialismo histórico, por la estructura misma de sus categorías, es la teoría de la sociedad burguesa. Su aplicación a sociedades precapitalistas significa considerarlas, desde el punto de vista del dinamismo emergente de la sociedad burguesa, como sus precondiciones históricas. Sólo en la sociedad capitalista las categorías del materialismo histórico dejan de ser meras categorías de interpretación y reconstrucción (desde el punto de vista de otra historia) y se convierten en elementos constitutivos de la autocomprensión de los agentes de la sociedad considerada. pensable para asegurar el equilibrio entre la producción y el consumo, por lo menos en una economía dinámi$\mathrm{ca}$, y en este sentido es una 'fuerza productiva' ${ }^{8}$. Y las cuestiones relativas a esta articulación básica de la sociedad son ideológicas: la elección de un marco teórico y conceptual depende intrínsecamente de la 'voluntad colectiva' (para usar el término de Gramsci), de una perspectiva elegida y declarada de desarrollo futuro.

No se sigue que en la teoría social 'todo se valga', ni que la discusión y la crítica puramente teóricas sean impertinentes en su terreno. No todo es posible a cada momento, y sólo unas pocas de las cosas 'posibles' son socialmente significativas, es decir, que articulan y expresan reclamos y empeños sociales existentes o por lo menos movilizables. Marx impone estrictos requisitos para una 'teoría crítica' de la sociedad: su marco conceptual debe permitir explicar los conflictos y antinomias recurrentes, empíricamente observables, de un proceso de reproducción social determinado e indicar las posibilidades de su transformación en una determinada dirección. Éstos no son postulados vacíos, y su cumplimiento no es asunto de 'voluntad'. Plantean una fuerte postura teórica, en principio confirmable o refutable empíricamente, abierta a la evaluación crítica. Pero la pretensión básica de la teoría es práctica: llevar a determinadas fuerzas sociales a la 'conciencia de sí', al entendimiento de su propia situación desde el punto de vista de sus intereses y necesidades 'reales' 9 .Y es perfectamente posible que en

\footnotetext{
${ }^{8}$ En este contexto, sin embargo, vale la pena señalar que Marx mismo ha tratado, en parte explícitamente al llamarlos así, en parte implícitamente al discutirlos, al comercio y al mercado mundial como 'fuerzas productivas' respecto a periodos precisos del desarrollo histórico. Véase por ejemplo, Grundrisse, pp. 188, 215 [en español, esta obra la publicó Siglo XXI con el nombre de Elementos fundamentales para la crítica de la economía politica]; Werke, vol. 25, pp. 345, 348349 , etcétera.

${ }^{9}$ Esta primacía de lo práctico sobre lo teórico está metodológicamente presente en la teoría crítica, entre otros lugares en el hecho de que mientras la teoría está formulada en un lenguaje descriptivo y a través de afirmaciones empíricamente comprobables, no puede imponer ningún plazo temporal estricto para sus supuestas 'predicciones. Precisamente por el hecho de que la teoría crítica de la sociedad no es una profecía social, es imposible, en un sentido teórico fuerte, 'falsificarla.' Falsificación' podría aquí significar simplemente el proceso de convertirse en socialmente obsolescente, es decir, incapaz de servir como vehículo cultural de la movilización de fuerzas sociales.
} 
un momento dado existan varias teorías distintas que pretendan razonablemente satisfacer estos requisitos teóricos y prácticos: no existen razones lógicas o metafísicas que garanticen que las fuerzas sociales interesadas o involucradas en una transformación radical de la sociedad presente tengan necesidades idénticas —ni que representen, incluso, prima facie, alternativas compatibles. La pluralidad de teorías críticas radicales puede ser un hecho tan normal de la vida ideológica como la pluralidad de teorías sociales que articulan actitudes básicamente distintas (críticas versus conservadoras) respecto a la realidad social, pero que cumplan, todas, con las normas elementales de 'cientificidad' históricamente válidas en el periodo considerado, aunque las interpreten e incorporen de distintas maneras.

Estas observaciones metodológicas, sin embargo, ya nos han llevado de la cuestión de la diacronía histórica a los problemas de la sincronía. Antes de tratarlos con más detalle, debemos señalar algunas de las consecuencias que tiene la interpretación aquí propuesta de 'fuerzas productivas' (junto con la interpretación de las relaciones de producción que conlleva) para la comprensión de la continuidad y del progreso históricos.

La vinculación empírica directa de estas dos nociones, que Marx realiza mediante el concepto de 'desarrollo de las fuerzas productivas', es insostenible a la luz de las consideraciones anteriores. La visión marxiana de continuidad se mantiene profundamente hincada en la tradición hegeliana. Concibe la continuidad de la historia como la preservación (Erhaltung) de una sustancia que atraviesa una constante expansión y universalización al ser transformada incesantemente en sujeto y viceversa. Pero el paradigma de la producción (a través de las nociones de objetivación y apropiación) postula la historia humana como el proceso material de una incesante transmisión de la tradición en el sentido pleno: la continuidad es el

En este posible proceso de 'refutación práctica', sin embargo, los méritos explicativos y las dificultades de la teoría deberían cumplir un papel decisivo (una teoría que sólo exprese demandas actuales, pero sea incapaz de explicar la situación de sus sujetos o de ofrecer una perspectiva realista de su transformación, es 'ideología' en el sentido peyorativo de la palabra) $s i$ sus destinatarios se comportan de manera racional.

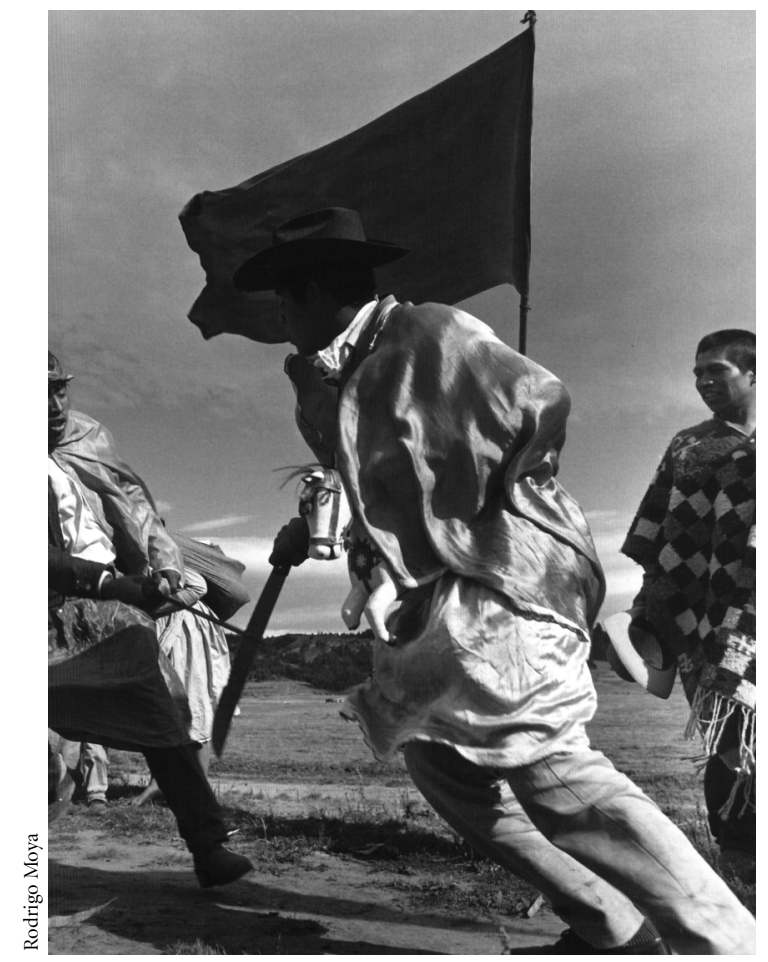

Sierra Chichinahuatzin, Estado de México, ca. 1964.

rasgo inmanente constitutivo de la historia, porque la vida humana sólo es posible mediante la adquisición e interiorización de algunos de los resultados objetivados del desarrollo previo. Pero 'apropiación' implica un proceso selectivo que no se puede describir como simple preservación: es heredar (Ererbung) el pasado dominando (Eroberung) sus resultados de acuerdo con las necesidades del presente. La discontinuidad no es, como se deduce de toda la concepción de Marx, la negación abstracta de la continuidad. Pero habría que agregar: tampoco es un patrón cambiante sobreimpuesto a un material que atravesaría esencialmente un 'crecimiento' unilineal. La discontinuidad histórica acarrea un cambio en aquellos 'criterios de selección' mediante los cuales las generaciones presentes se apropian y reproducen activamente los 'productos' del pasado. La discontinuidad existe en la historia como cambio de dirección de la continuidad histórica.

Es por lo tanto imposible 'inferir' el progreso de la continuidad empírica de la historia. El concepto de progreso 
construye una 'unidad superior' a partir de la continuidad heterónoma de la historia, y la construye desde el punto de vista de un futuro deseado determinado. En tanto construcción de la unidad dentro de la historia, las teorías del progreso histórico representan una de las maneras de proclamar la validez universal de valores y fines prácticos que brotan del suelo de una sociedad y una cultura que conocen su particularidad histórica. En tanto construcción de unidad desde el punto de vista de un futuro determinado, el 'progreso' no sólo implica elegir una opción particular de desarrollo, es decir, considerar el futuro deseado como dinámico, sino al mismo tiempo vincular su dinamismo no sólo con determinadas tendencias del pasado (siempre ineludible), sino con aquellas tendencias enraizadas en el pasado que estén, en la sociedad presente, investidas (práctica e ideológicamente) con un carácter de valor definido. (Concretamente, en la medida en que Marx caracteriza el progreso histórico bajo el signo de 'desarrollo de las fuerzas productivas', esto significa una aseveración, desde el punto de vista del socialismo, de la tendencia hacia un mayor dinamismo de las necesidades y capacidades productivas y de las necesidades humanas, hacia una mayor reducción del tiempo de trabajo necesario y hacia el cambio tecnológico en la medida en que éste sirva a estos objetivos.) La historiosofía del progreso interpreta el futuro como 'consumación, 'actualización real' de algunos propósitos de valor que ya están activos (si bien en una forma alterada) en su prehistoria inmediata.

El progreso nunca se puede inferir simplemente de la continuidad empírica de la historia, porque lo que su idea plantea prácticamente es una continuidad definida de valores entre un futuro entendido dinámicamente y su 'pasado' inmediato. Esto es, sin embargo, una 'elección' y, cuando algunos críticos radicales de Marx caracterizan su planteamiento como 'conservador', como cautivo de los prejuicios de la Ilustración, etc., sostienen un argumento significativo; la pregunta sería más bien saber hasta qué punto esta crítica deriva del autoengaño de los críticos en lo que toca a sus propios programas y opciones positivos. La 'elección' involucrada no puede ser, por supuesto, una decisión irracional, y definitivamente no lo es en el caso de Marx. Ésta depende del análisis de las raíces sociales sistemáticas de la miseria y el sufrimiento humanos en la sociedad burguesa actual, y de los caminos posibles y fuerzas disponibles para su superación. Pero, de todas maneras, sigue siendo una elección; y no sólo en el sentido trivial de que es imposible 'deducir' una solución histórica del diagnóstico mismo de una crisis social (de lo cual Marx estaba consciente ya que veía el socialismo como la alternativa al colapso de la civilización), sino antes que nada por la pretensión de tal solución a la validez e importancia universales y paradigmáticas - pretensión que se afirma y articula precisamente mediante la idea de progreso histórico.

El historicismo radical de Marx rechaza cualquier intento de justificación trascendente, suprahistórica, de esta pretensión, pero su propio esfuerzo por justificarla empíricamente, al describir la historia humana como el proceso dialéctico de creación y acumulación (incluso en una forma contradictoria) de valores que sólo pueden alcanzar su 'pleno florecimiento' y su realización universal dentro del socialismo, también falla. Esta descripción 'empírica' de la historia parece funcionar sólo gracias a una construcción y estructuración previas del tiempo histórico en función de los valores ya elegidos. Entre sociedades y culturas coexistentes, Marx elige el capitalismo como aquella cuyas antinomias se pueden resolver en el sentido de una emancipación no sólo particular y localista, sino humana. En el tiempo histórico 'real' el capitalismo es, por lo tanto, 'posterior', más desarrollado que las sociedades que existen simultáneamente ( $\mathrm{y}$, de manera aún más radical, todo el desarrollo social occidental es 'posterior' a lo que él llama 'modo asiático de producción'). Al tratar de mantenerse fiel al historicismo radical implícito en el mismo 'paradigma de la producción', uno se ve obligado a renunciar a este procedimiento circular. La teoría del progreso humano no es la 'ciencia positiva' de la historia. Sólo tiene sentido como parte del esfuerzo histórico práctico para darle a la historia humana el significado de progreso, es decir, para crear condiciones bajo las cuales los individuos (todos los individuos) puedan participar de manera efectiva e igual en las decisiones que determinan cómo darle forma al marco socioinstitucional de sus vidas para vivir mejor, de acuerdo con sus propios valores y necesidades. 
Al formular este objetivo histórico y especificar las condiciones de su realización, la teoría marxiana del socialismo en sí misma representa una elección de determinados valores entre los que existen en la sociedad contemporánea, una elección condicionada a la vez por la situación existencial de sus (propuestos) destinatarios y por la condición estructural de esta sociedad. Esta elección sólo puede justificarse finalmente en la práctica mediante la realización de su pretensión de universalidad, al conducir hacia una unificación práctica del género humano sobre las bases que establece. No hay garantías metahistóricas ni del 'éxito' de esta empresa, ni de su 'deseabilidad'. No se puede decidir a priori y en teoría si la asociación de productores libres y el desarrollo de individuos pluridimensionales constituye, o no, una 'sociedad buena'. Esto sólo lo pueden decidir aquellos que están involucrados en el intento práctico de su realización. La cuestión no es retórica. Nadie puede decir anticipadamente si, por ejemplo, todo el esfuerzo y responsabilidad requeridos por la participación real en las decisiones sociales dentro del marco de una interacción global es conmensurable con sus 'beneficios' para los individuos involucrados (sin olvidar, por supuesto, la posibilidad de que, en estas circunstancias modificadas, los individuos puedan considerar tal esfuerzo y responsabilidad como un valor en sí y no como una carga adicional). El proyecto radical del socialismo en el sentido marxiano no puede ofrecer pruebas absolutas, indubitables, de su 'justeza, 'sólo' se funda en la 'evidencia experimentada vivencialmente' de lo 'injusto' del estado presente de la sociedad, expresada a la vez en sufrimiento pasivo y en necesidad activa de un cambio.

Aquí, regresamos otra vez de las cuestiones de una teoría de la historia ${ }^{10}$ a las de un análisis social crítico. Al

\footnotetext{
${ }^{10}$ La interpretación aquí indicada de 'progreso histórico' apunta, sin embargo, hacia una de las dificultades teóricas y prácticas fundamentales que debe enfrentar hoy día la teoría radical crítica de la sociedad de tradición marxista. Cuando Marx identificó el progreso con la continuidad empírica de la historia, no sólo se trataba, de su parte, de un caso de "falacia naturalista", sino que dependió de supuestos y expectativas históricas específicas de su teoría. La 'elección' del capitalismo (junto con un sistema de valores que sólo podía llegar a existir, como ocurrió, bajo este sistema) podía parecerle a Marx la simple estipulación de un hecho histórico, ya que él presuponía que el capitalismo está en un proceso inarrestable de conquista de todo el planeta y de
}

respecto tenemos que preguntar antes que nada: ¿qué tanto afecta al significado del concepto crítico central de Marx, el de la contradicción entre fuerzas productivas y relaciones de producción, una 'radicalización' del paradigma de la producción, en el sentido aquí esbozado?

La intención básica involucrada en la idea de esta contradicción en la teoría madura de Marx es la de establecer una conexión directa entre las condiciones objetivas, que hacen posible la transformación radical de la sociedad, y aquellas fuerzas sociales capaces de realizar tal transformación. Si no se establece esta conexión, la teoría degenera en un análisis puramente 'cientificista' de las disfunciones inherentes al sistema de reproducción, sin poder dar cuenta de ninguna motivación para un cambio (de manera que puede 'predecir' un colapso pero no promover en la práctica una transformación radical), o en una expresión 'ideológica' de aspiraciones revolucionarias 'sentidas', sin poder demostrar que son reales y realizables. Sólo se puede fundamentar la afirmación de que la teoría 'supera la filosofía', tanto en el sentido de una práctica comunicativa de autocomprensión (expresión y articulación de los intereses de la clase trabajadora) como en el de una 'ciencia positiva' de la sociedad capitalista, si se puede mostrar que las aspiraciones radicales que desafían el sistema existente de relaciones sociales son el resultado directo y necesario de las disfunciones estructurales de su reproducción, revelando así la posibilidad de su reorganización revolucionaria. $\mathrm{O}$, para expresarlo en términos más fuertes: hay que demostrar que esos mismos intereses y necesidades radicales constituyen el elemento

transformación de todas las sociedades tradicionales, a fin de cuenta, en sociedades capitalistas (o quizás directamente socialistas). En este sentido podía válidamente considerar el sistema de valores del capitalismo como empíricamente universal - por la fuerza de una necesidad histórica prácticamente obvia para él. Tales expectativas históricas de Marx, sin embargo, resultaron, con mucho, demasiado 'optimistas'. Aunque el capitalismo ha logrado convertirse en un 'sistema-mundo', al derrumbar a su paso todas las barreras y destruir el tejido social de las sociedades tradicionales, su 'progreso' no desembocó en un desarrollo capitalista autóctono en muchas partes del mundo, sino que produjo economías y sociedades profundamente truncadas e involucionadas o desbalanceadas y 'duales'. Todos los que tratan de prolongar la tradición marxista tienen que reconsiderar la idea marxiana de la función 'histórica mundial' del capitalismo a la luz de aquellas experiencias históricas, ya que para ellos tal idea cumple sin duda un papel central, constitutivo. 


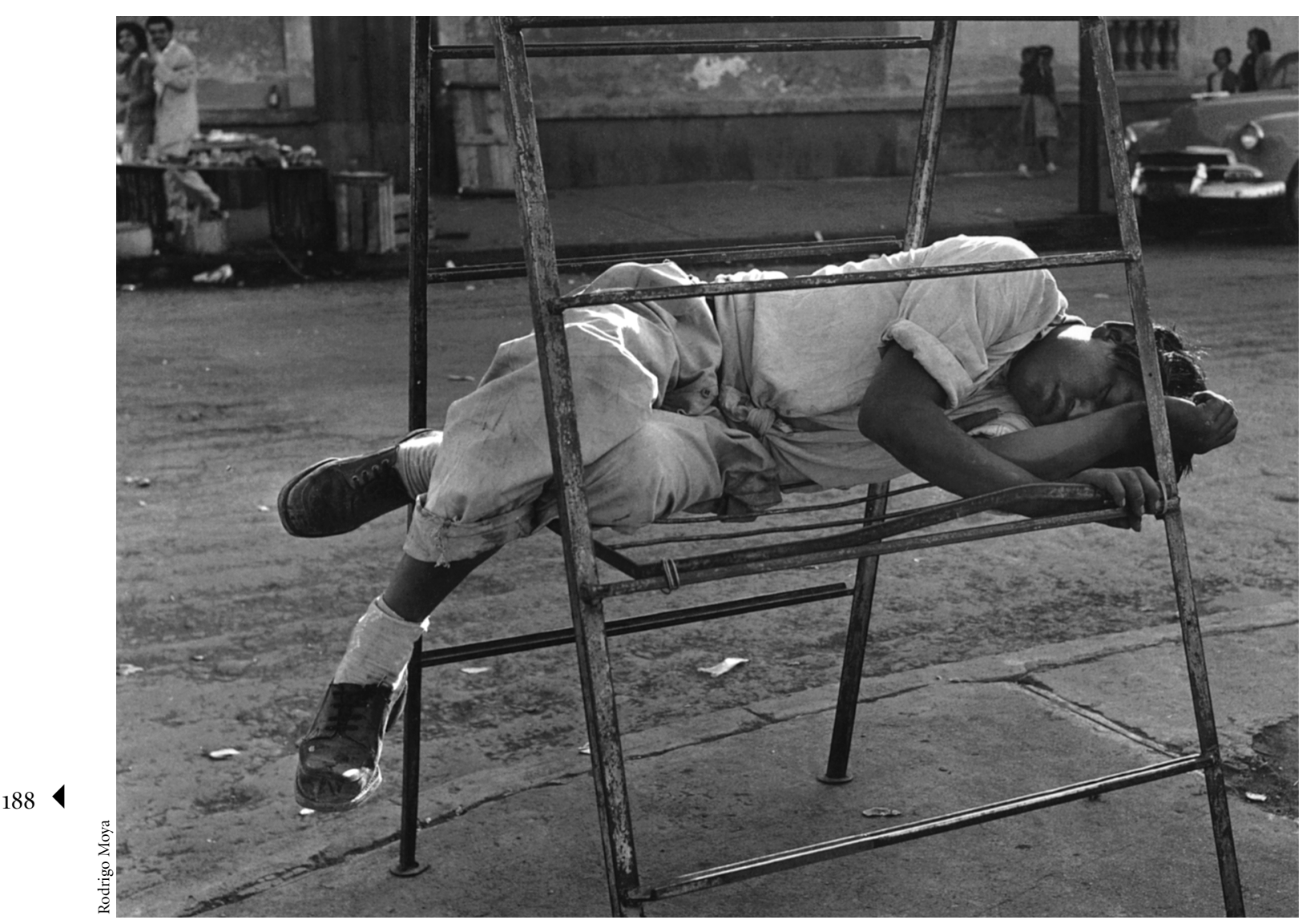

Xochimilco, ciudad de México, ca. 1957.

medular de las 'contradicciones objetivas' del sistema. El famoso enunciado de Marx: "De todos los instrumentos de producción, la mayor fuerza productiva es la propia clase revolucionaria", resulta central y constitutivo en la construcción marxiana de la 'contradicción' entre fuerzas productivas y relaciones de producción.

En qué sentido se puede considerar a la 'clase revolucionaria' como un elemento de las 'fuerzas productivas' es un problema que, bajo cualquier interpretación, despierta serias dudas ${ }^{11}$. Una de las opciones de interpretación

${ }^{11}$ Véase, por ejemplo, Jürgen Habermas, Legitimationsprobleme im Spätkapitalismus, Suhrkamp, Frankfurt, 1973, esp. pp. 73-79; A. Wellmer, Kritische Gessellschaftstheorie und Positivismus (sin lugar, fecha ni editorial en el original), pp. 99-104; A.Wildt, "Produktivkräfte es que su subsunción bajo este último concepto implica asumir que son las capacidades y calificaciones productivas de los trabajadores lo que conforma 'la mayor fuerza productiva. Esta propuesta es, sin duda, teóricamente coherente. Pero entonces una 'contradicción' entre fuerzas productivas y relaciones de producción significaría aceptar simultáneamente que: 1) el capitalismo se enfrenta con dificultades sistemáticas, que empeoran a medida que se desarrolla, para reproducir una fuerza de trabajo con una 'especificación histórica correspondiente'12; y

und soziale Umwalzung", en U. Jaeggi y A. Honneth (eds.), Theorien des Historischen Materialismus, Suhrkamp, Frankfurt, 1977, pp. 216 226, etcétera.

12 Esta idea figura sin duda en El capital, donde Marx describe la 'con- 
2) que esas dificultades (presentes, por ejemplo, en los hechos de desempleo estructural), junto con los cambios en el carácter y contenido de las calificaciones técnicas, generan directamente en los productores inmediatos tales aspiraciones radicales que no pueden ser satisfechas dentro del sistema de relaciones sociales existente. Estas presuposiciones son lógicamente coherentes, pero —a pesar de varios intentos de darles concretización histórica ${ }^{13}$ no parecen surgir de los hechos del desarrollo histórico, y en cualquier caso representarían una base muy estrecha para la teoría crítica (tanto respecto al carácter de la motivación radical como a su extensión social). Por el otro lado, si el citado enunciado de Marx significa que los trabajadores como clase son 'la mayor fuerza productiva'14, sería entonces el conflicto consciente y la lucha de clases real lo que primero constituiría la 'contradicción' entre fuerzas productivas y relaciones de producción. Esto, sin embargo, es lógicamente incompatible con la insistencia de Marx en el carácter 'objetivo' de esta contradicción, en su carácter independiente de la voluntad y de la conciencia' de todos los individuos participantes.

Si bien es fácil encontrar en Marx líneas de pensamiento que se pueden asimilar a una u otra de las interpreta-

tradicción absoluta’ de la sociedad burguesa como la que existe entre, por un lado, la "fluidez de funciones, la movilidad generalizada de los trabajadores", necesaria bajo las condiciones de un dinamismo incesante de la producción y, por el otro lado, la "vieja división del trabajo con sus particularismos cosificados", que el sistema de dominación capitalista impone a la producción (cfr. Werke, vol. 23, p. 511).

${ }^{13}$ El más nuevo y significativo de estos intentos fue la teoría de la "nueva clase obrera" desarrollada en la primera mitad de la década de 1960 por varios teóricos franceses radicales. Véase S. Mallet, La nouvelle classe ouvrière, París, 1963; P. Belleville, Une nouvelle classe ouvrière, París, 1964; M. Kravetz, "Naissance d'un syndicalisme étudiant", Les Temps Modernes, 1964, pp.1447-1475; A. Gorz, Stratégie ouvrière et néocapitalisme, París, 1965.

${ }^{14}$ En el pensamiento de Marx hay, de nuevo, elementos que pudieran apoyar tal interpretación. Véanse en particular sus comentarios sobre el papel decisivo de la lucha de clase del proletariado para impulsar el progreso tecnológico bajo el capitalismo ( $\mathrm{y}$ también para determinar las formas y los límites concretos del plustrabajo y del plusvalor): "De 1825 en adelante, la invención y aplicación de máquinas llegó a ser sólo el resultado de la guerra entre empresarios y trabajadores" (Werke, vol. 4, p. 551). La misma idea vuelve en El capital: "Se podría escribir una historia entera de todas las invenciones que, desde 1830, sólo nacieron para servir de armas al capital contra las rebeliones de los obreros" (Werke, vol. 23, p. 459). Véase también la discusión detallada de la "invención y aplicación de máquinas contra las huelgas, etc." en el manuscrito de 1861-1863, MEGA, 2a parte, vol. 3/1, pp. 312-314. ciones anteriores, es bastante obvio que el argumento fundamental de sus últimas obras sigue otro curso. Las disfunciones de la economía capitalista, que se expresan, por un lado, en sus crisis de sobreproducción cada vez más profundas y, por el otro, en el carácter antagónico del proceso de acumulación, se traducen directamente en una amenaza constante a los niveles de vida elementales de las masas básicas de trabajadores (entendidos como los niveles de necesidades "mínimas" que cambian históricamente, pero con mucha lentitud, y cuya satisfacción peligra regularmente en tiempos de crisis). Simultáneamente, las mismas causas producen un crecimiento constante del 'ejército industrial de reserva', cuyos miembros se ven arrojados a la indigencia, la pobreza desesperada. "La ley por la cual una cantidad constantemente creciente de medios de producción, gracias al aumento de la productividad del trabajo social, puede ser puesta en movimiento por una cantidad de fuerza humana progresivamente decreciente, esta ley, en un contexto capitalista - en el cual el trabajador no emplea los medios de producción sino que los medios de producción emplean al trabajador - se expresa de la siguiente manera: mientras más alta es la productividad del trabajo, mayor es la presión de los trabajadores sobre sus medios de empleo, y más precarias, por lo tanto, se vuelven sus condiciones de vida"15. Así que las relaciones capitalistas de producción están en contradicción con el desarrollo de las fuerzas productivas, cuyo elemento principal es la misma 'clase revolucionaria', no en el sentido de su creciente incapacidad para garantizar la reproducción de las calificaciones técnicas necesarias de los trabajadores, ni en el sentido de su antagonismo directo con aquellas aspiraciones en torno a las cuales los trabajadores asalariados se constituyen conscientemente (políticamente) como clase, sino en el sentido de la inestabilidad y precariedad cada vez más profundas de la reproducción de la clase trabajadora como masa de fuerza de trabajo, como 'población productiva' ${ }^{16}$. En este sentido las disfunciones sistemáticas

\footnotetext{
${ }^{15}$ Werke, vol. 23, p. 674.

${ }^{16}$ En este sentido hay una relación entre las formulaciones anteriores de Marx sobre la clase revolucionaria como la principal fuerza productiva y sus afirmaciones teóricas más tardías según las cuales
} 
del proceso capitalista de reproducción producen inevitable y directamente entre los trabajadores motivaciones radicales que trascienden el sistema, y esas son simplemente idénticas a la aspiración 'natural' de cada individuo a garantizar la satisfacción de sus necesidades básicas, 'elementales'.

No hacen falta argumentos específicos para mostrar que esta construcción marxiana no se puede aplicar a las condiciones del 'neocapitalismo'. Pero una crítica que sólo se limitara al carácter hoy día obsoleto de esta teoría particular de Marx, perdería de vista algunos problemas metodológicos más generales y básicos que subyacen a esta construcción particular y que determinan el carácter global de la teoría crítica tal como Marx la elaboró, incluyendo las antinomias antes mencionadas.

Cuando Marx establece el vínculo entre las condiciones objetivas y las motivaciones subjetivas del cambio radical a través de la 'subsunción' de la clase trabajadora bajo la noción de 'fuerza productiva', transforma en realidad a los destinatarios y sujetos de su teoría en un 'objeto construido' por la teoría. En un sentido particular, este paso está conectado orgánicamente con la idea misma de teoría crítica. Esta última no es una simple sistematización de las aspiraciones conscientes, al menos 'vividas', de los asalariados; se propone llevarlos a la conciencia de sí, lo cual eo ipso presupone una distinción de alguna clase entre conciencia 'empírica' y conciencia 'atribuida' (zugerechnetes). Como teoría crítica de la sociedad capitalista, el marxismo es también una 'crítica' de su sujeto, de la clase obrera que forma parte integrante de esta sociedad. Los individuos y sus grupos están 'determinados desde afuera', no sólo respecto a su situación social objetiva, sino también en su 'subjetividad'. Lo que ellos vienen a reconocer conscientemente como sus necesidades, aspiraciones, intereses, está canalizado de una manera definida - tanto espontáneamente (de ahí la categoría de conciencia 'fetichista') como a través de las ideologías dominantes - por las relaciones existentes de dominación social y en concordancia con ellas. La teoría crítica

es en "el desarrollo de la población donde se resume el desarrollo de todas las fuerzas productivas" (Grundrisse, p. 498). se asume como una parte de aquel proceso de aprendizaje práctico que interrumpe esta socialización (integración) cotidiana 'normal' de los trabajadores dentro de la sociedad capitalista. La teoría de la clase obrera tiene que ser, en cierto sentido, una teoría sobre la clase obrera: el camino de la comprensión de sí misma es el de la explicación crítica de la conducta 'normal' que revela — desde la perspectiva de una alternativa, sistemáticamente cancelada por las relaciones sociales dominantes, pero prácticamente realizable - a la vez su necesidad social condicional y su atrocidad histórica.

Sin embargo, cuando Marx establece esta conexión entre la comprensión de sí y la explicación mediante la transformación del 'sujeto' (destinatario) de la teoría crítica en 'objeto construido' por ella, da un paso más. Asimila la distinción entre conciencia 'empírica', inducida por el sistema, y conciencia 'atribuida' (adecuada a los objetivos socialistas) a la distinción entre apariencia (o incluso ilusión) y realidad, por un lado; y entre ignorancia y conocimiento verdadero, por el otro. Las necesidades, intereses $\mathrm{y}$ aspiraciones de los trabajadores, que resultan de su integración objetiva en la sociedad capitalista, del hecho de ser una clase de esta sociedad, se ven rebajadas al estatus de simples fenómenos psicológicos subjetivos ${ }^{17}$, contrapuestos con un concepto en sí contradictorio de 'interés objetivo', un interés que es categóricamente independiente de la conciencia y la voluntad. El proceso mediante el cual la clase trabajadora alcanza la conciencia de sí, es decir, alcanza su autonomía práctica e histórica, se vuelve sinónimo del reconocimiento de aquellos intereses 'reales' que la teoría le adscribe como características esenciales permanentes de su posición de simple elemento en el proceso 'automático' espontáneo de la reproducción ca-

\footnotetext{
${ }^{17}$ La noción marxiana de 'fetichismo', en su constante ambigüedad entre una referencia objetiva y una subjetiva, ilustra bien las dificultades teóricas de esta posición. Con Lukács, quien en su Historia y conciencia de clase sacó las consecuencias radicales de algunas de las tendencias presentes en Marx, la crítica de la conciencia fetichista lleva a formulaciones que implican la reversión simple de un dualismo platónico entre realidad inmutable y apariencias cambiantes: "Las tendencias de desarrollo de la historia forman una realidad superior a los 'hechos' empíricos"; "el proceso total... representa, contra los hechos, la realidad auténtica, la superior”, etc., Werke, Neuwied, vol. 2, 1968, pp. 366-367, 370.
} 
pitalista, como mero objeto. La autoeducación práctica a través de experiencias comunitarias y comunicativas de lucha social se identifica con el aprendizaje de la verdad de un cuerpo de conocimiento preexistente. La teoría crítica, entonces (con perfecta coherencia), puede pretender al mismo tiempo que rebasa la filosofía tanto en el sentido de una práctica dialógica y comunicativa de autoeducación como en el de una 'ciencia positiva', porque la segunda no sólo contiene de antemano todos los resultados esenciales que pueden y deben ser alcanzados por la primera, sino que propone además una demostración de la necesidad de su obtención (por lo menos, como única alternativa a la autodestrucción). Entonces, pero sólo entonces, no hay contradicción entre el hecho de que la teoría postule como su única meta 'educar a los trabajadores a actuar con independencia' $18 \mathrm{y}$, al mismo tiempo, anuncie que nada tiene que ver con "qué objetivo contempla, en un momento dado, tal o cual miembro del proletariado, o incluso el proletariado en su conjunto" 19 — porque en este caso actuar 'con independencia' sólo significa actuar tal como "está históricamente obligado a actuar conforme a su propio ser (Sein)"20. La 'subjetivación' práctica del proletariado (su conversión en un agente histórico que actúa con autonomía) es entonces idéntica a la realización de su completa 'objetivización' teórica; la libertad es la conciencia de una necesidad preestablecida. En este sentido, pero sólo en este sentido, la forma marxiana de la teoría crítica contiene ya —en su propia estructura - la posibilidad abstracta de la práctica política del 'sustitucionismo'.

Pero en el momento en que la teoría crítica se postula a sí misma como esta forma de unidad realizada entre autoeducación comunicativa y ciencia positiva, la presuposición de un sujeto exclusivo único y unitario, de la transformación revolucionaria deja de ser la guía práctica de la teoría que puede y debe ser sometida a la prueba de las experiencias históricas. La suposición de tal sujeto se convierte ahora en un postulado de la teoría, impuesto por su estructura propia, en una condición categórica

\footnotetext{
${ }^{18}$ Carta a Lassalle, 1868; Werke, vol. 32, p. 570

${ }_{19}$ Werke, vol. 2, p. 38.

${ }^{20}$ Idem.
}

de su posibilidad. En este sentido, Lukács sólo derivó consecuencias finales cuando caracterizó la 'construcción' del proletariado como la concretización y realización históricas del postulado de la unidad sujeto-objeto en la filosofía clásica.

Sin embargo, si la teoría está comprometida incondicionalmente con la concepción de un agente revolucionario singular y unitario, predestinado por su situación objetiva a ser el 'vehículo' del cambio social radical, la gama de motivaciones radicales posibles resulta por principio delimitada, reducida a una negatividad abstracta. En efecto, del proletariado como elemento y objeto del proceso capitalista de reproducción, como 'construcción' de su ciencia, sólo se puede afirmar, en el mejor de los casos, que le caracterizan aquellos 'móviles' que están dirigidos contra el capitalismo (en el sentido de que la realización de sus 'intereses objetivos' es imposible bajo estas condiciones). Pero faltan entonces motivos a favor de una sociedad socialista, o intenciones específicas orientadas hacia ésta. (Esto resulta obviamente verdadero en el caso de la presuposición marxista según la cual el esfuerzo para garantizar la satisfacción segura de las necesidades elementales constituye la motivación radical básica.) Mientras más determinista se vuelve la teoría respecto a la existencia de un móvil revolucionario, menos determinado se vuelve el contenido de tales motivaciones en cuanto al carácter de esta transformación radical. Si el vínculo entre las condiciones objetivas y las intenciones radicales se establece por medio de la noción de 'intereses objetivos', entonces la teoría crítica exige salvaguardias adicionales —más allá de las motivaciones radicales - para garantizar el carácter socialista del cambio histórico planteado; debe hacer del socialismo la alternativa única, teleológicamente predeterminada, al capitalismo. Es precisamente la interpretación estrictamente determinista del 'presente' la que invoca la interpretación finalista del 'futuro' de la historia ${ }^{21}$. La concrescencia paradójica del determinismo

\footnotetext{
${ }^{21}$ Este complemento finalista es por completo necesario ya que la concepción de la "motivación negativa" implica eo ipso que cada logro práctico, cada victoria táctica del movimiento obrero (excepto la última) disminuye y calma las motivaciones radicales de esta clase. Como estrategia, esta concepción implica una postura puramente defensiva
} 
y el finalismo en la teoría de la 'reificación' de Marx, que él elabora al mismo tiempo que la comprensión reductivista-'negativista' de las motivaciones radicales ${ }^{22}$ y que la interpretación 'cientificista' de su teoría crítica misma, todas estas tendencias aparentemente independientes $\mathrm{e}$ inconexas de la oeuvre tardía de Marx, constituyen una constelación teórica. Con sus vínculos mutuos, configuran no sólo la forma más elaborada, hasta hoy, de la teo-

en cuanto a la posibilidad de cambiar la situación de los trabajadores bajo el capitalismo, con una profunda "desconfianza" respecto a cualquier conquista institucional en este terreno. (Esta postura ya está claramente ilustrada en la actitud de Marx hacia los sindicatos como "compañías de seguro" de los trabajadores, "cuyo... único propósito es impedir que los salarios se hundan por debajo de su nivel tradicional en cada rama de empleo, dificultar la depreciación del precio de la fuerza de trabajo por debajo de su valor." Resultate..., p. 236.) Por el otro lado, atribuye un valor intrínseco a aquellas organizaciones de la clase obrera que aparecen como depositarias de sus intereses 'reales' (es decir, de sus intenciones revolucionarias tales y como se las atribuye la teoría 'correcta') y que constituyen, por lo tanto, sus contra-instituciones en el capitalismo - y eso, cualquiera sea la situación vital, la posición, la actividad concreta de los trabajadores dentro de esas organizaciones (un asunto considerado fundamentalmente como de conveniencia política). Pero las opiniones de Marx al respecto pertenecen todavía, en definitiva, a la infancia del movimiento obrero organizado. Él todavía presupone que estas 'contra-instituciones' del proletariado deberían tener el carácter de organizaciones de masas nacionales e internacionales en constante expansión, sin enfrentar el problema de que la existencia de estas organizaciones, al implicar invariablemente el progreso de 'conquistas' definidas de la clase obrera dentro del capitalismo, crean un cierto grado de 'interesamiento' del proletariado en el capitalismo. (La clase obrera ya puede perder no sólo sus 'cadenas' sino también sus instituciones existentes.) En este sentido, la semilla del gran cisma del movimiento obrero se puede encontrar en algunas tensiones en los puntos de vista del propio Marx (lo cual no implica, por supuesto, la posición imbécil que cree posible 'deducir' el cisma como resultado necesario de las teorías de Marx.) La primera, probablemente, en enfrentar con seriedad este dilema fue Rosa Luxemburgo.

22 Como ya lo señalamos, los Grundrisse es el único trabajo en toda la obra de Marx en el cual se observa un esfuerzo coherente por llegar a una concepción de "motivaciones positivas" para el cambio radical (es decir, a un concepto de intenciones y necesidades radicales del proletariado tal que en su contenido trasciendan el capitalismo). Sin embargo, Grundrisse no sólo es un borrador fragmentario y parcialmente inconsistente, sino que presenta también, y precisamente en este aspecto, rasgos claramente utópicos. La concepción de las 'motivaciones positivas' se basa aquí en una perspectiva de un desarrollo industrial supuestamente inevitable, que tecnológicamente elimina, al final, la distinción entre trabajo físico y trabajo intelectual, entre tiempo de trabajo necesario y tiempo libre, etc. La transición de los Grundrisse a El capital, por problemática que sea en otros aspectos, significa, en este sentido, no sólo un paso hacia una mayor coherencia teórica, sino también una comprensión más realista del presente y de sus tendencias. ría crítica, sino también — a pesar de sus ambigüedades y dificultades internas - su forma más coherente.

Pero esta versión final de la teoría de Marx en El capital está en conflicto latente con aquellas intenciones teóricas y prácticas más generales indicadas (más que formuladas explícitamente) en sus trabajos tempranos, aquellas intenciones mediante las cuales realizaba su 'ruptura' con la tradición cultural del pasado - intenciones a las cuales nunca renunció y cuyas huellas vuelven a aparecer constantemente también en sus escritos tardíos. En el lenguaje de la filosofía estas intenciones básicas implican una comprensión radicalmente nueva de la intersubjetividad (y la correspondiente noción nueva de sujeto), con base en la cual se puede formular una nueva idea de racionalidad entendida como proyecto práctico, históricosocial. El 'materialismo histórico', en contraste con el 'individualismo abstracto' de la Ilustración y con las teorías del sujeto supraindividual del idealismo alemán clásico, mediante el paradigma de la producción como la unidad de la objetivación y la apropiación, sugiere una comprensión modificada de la intersubjetividad. Postula que esta última constituye una objetividad social externa que, por un lado, 'determina' desde fuera y trasciende a cada uno de los sujetos empíricos; pero por el otro, tiene este significado objetivo de ser el 'portador' de una intersubjetividad históricamente formada (en contraste con una presencia e influencia puramente físicas) sólo en la medida en que se ve incesantemente retransformada en las necesidades y capacidades subjetivas de individuos empíricos, a través de sus propias actividades e intercambios sociales conscientes y deliberados. Y la objetividad social, el mundo de objetos materiales creado por los hombres, 'trasciende' incluso a la totalidad de los sujetos empíricos coexistentes, antes que nada en el sentido de que siempre ofrece y hace posible otros 'usos' y 'empleos' distintos de aquellos usos efectivamente realizados en un momento histórico dado, es decir, en la medida en que la actividad de los individuos sociales no tiene sólo un carácter reproductivo sino también poiético-creativo. Los individuos empíricos son los únicos sujetos de la historia porque el mundo entero de objetividad social es su creación y sólo tiene un sentido humano-social en relación con sus prácticas. Pero son irrevocablemente seres limitados y finitos 


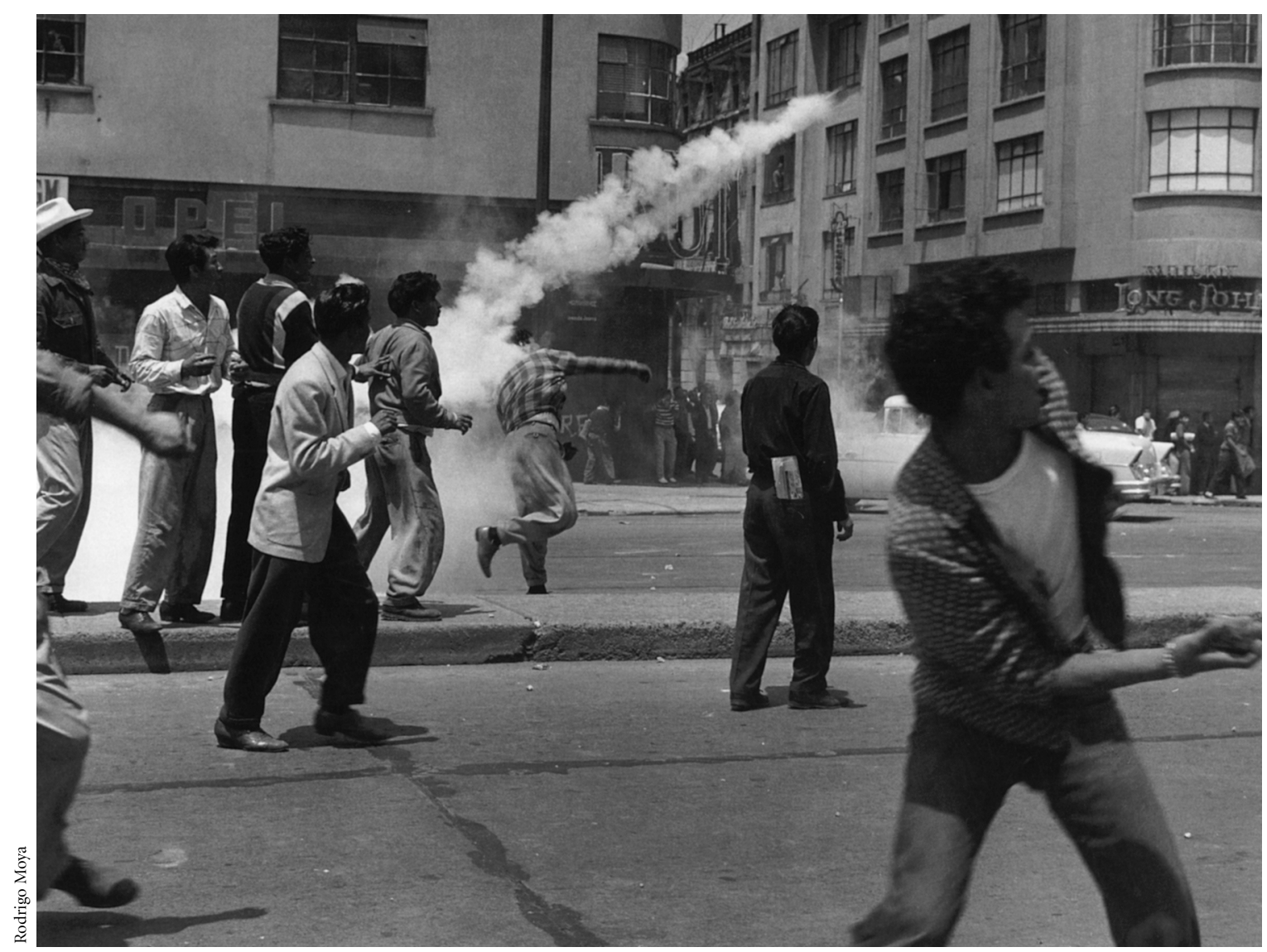

Movilizaciones magisteriales y estudiantiles. Avenida Juárez, ciudad de México, 1958.

porque lo que son y pueden ser está siempre delimitado $y$ circunscrito (como el campo de elecciones individuales y de alternativas histórico-sociales posibles) por aquellas 'circunstancias sociales' que encuentran ya hechas. La nueva noción de intersubjetividad implica una noción diferente de 'sujeto', que conecta en una unidad las ideas de autonomía y de finitud humanas: “...los individuos ciertamente se hacen los unos a los otros, física y mentalmente, pero no se hacen a sí mismos"23.

Es esta unidad dialéctica — sugerida y filosóficamente señalada, más que elaborada en una teoría crítica de la presente etapa histórica, en las obras tempranas de

${ }^{23}$ Werke, vol. 3, p. 37.
Marx- la que se descompone en sus trabajos tardíos en un determinismo de los sujetos empíricos y un finalismo (teleología) del sujeto colectivo (una clase o la humanidad como el sujeto del "progreso" histórico) con el postulado abstracto de mediación entre los dos. En la medida en que la teoría marxista, hasta el final de la Segunda Guerra Mundial, conservó y desarrolló esencialmente las ideas gemelas de sujeto revolucionario único y unitario y de 'motivaciones radicales negativas' 24 , le era en el fondo

\footnotetext{
${ }^{24} \mathrm{El}$ anarcosindicalismo fue el primero que intentó, en dicho momento histórico, llegar a una teoría de 'motivaciones positivas' para la acción y el cambio social radical. Pero —en la medida en que tales intentos tuviesen del todo alguna base teórico-filosófica - tendían a basarse en un mito apoteótico del trabajo y la colectividad.
} 
imposible rebasar este dualismo, que se reproducía constantemente bajo las formas polarizadas del cientificismo positivista y de la filosofía de la praxis. Incluso la transformación más importante dentro de la teoría marxista —el reemplazo tácito del proletariado como único vehículo del cambio revolucionario por la 'humanidad' encarnada en el mundo de los valores y las objetivaciones culturales, un reemplazo efectivamente realizado por muchos representantes del marxismo 'occidental' (el Lukács tardío, Benjamin, Adorno, Marcuse, etc.) bajo el impacto directo de las experiencias históricas del fascismo y el estalinismo - dejó intacta esta estructura básica, aunque transformó la teoría de la 'emancipación' en una teoría de la 'liberación' (Rettung).

El 'neomarxismo' de la posguerra fue el primero en cuestionar estos postulados de manera explícita y general. La consolidación de la sociedad neocapitalista hizo que la perspectiva de una revolución basada en la inseguridad de la simple subsistencia se volviera en su mayor parte irrelevante para las realidades de las sociedades occidentales desarrolladas. Las experiencias de la Unión Soviética y de Europa Oriental desacreditaron profundamente la identificación del socialismo con 'una economía planificada sin crisis' (ausente en Marx, por cierto, pero históricamente acumulada en el concepto de transformación socialista). El surgimiento espontáneo de varios movimientos con objetivos radicales pero, al menos en parte, contradictorios, posterior a la desestabilización de las sociedades neocapitalistas al final de la década de 1960, convirtió la cuestión de las motivaciones radicales en un asunto de orientación política directa. El pensamiento marxista entró en su periodo de 'búsqueda del sujeto'. Esto significó, precisamente por las razones arriba señaladas, algo más que una reorientación práctica de la teoría a condiciones históricas modificadas; conllevaba una disolución de la construcción que le permitía articular y justificar su pretensión de validez. La posibilidad de la teoría crítica volvió a ser una cuestión; la 'crisis' del marxismo es ahora abierta y explícita.

El proyecto marxiano de una 'teoría de la revolución social' (distinta y opuesta tanto a una teoría sobre las revoluciones sociales como a una mera 'ideología' revolucionaria) es en su idea misma antinómica. En cuanto teoría de la revolución social, tiene que demostrar que la actividad humana colectiva y consciente puede cambiar radicalmente las condiciones actuales y el curso de la historia: tiene que disipar todas las ilusiones fetichistas que suponen poderes trascendentes y fines inmutables que determinan el destino del pueblo y de la humanidad. Tiene que ser una explicación y una comprensión de la historia radicalmente inmanentes, la negación decidida de la posibilidad de cualquier punto de vista metahistórico. Se ve obligada, por lo tanto, a considerar la conciencia como 'conciencia de una práctica existente', a considerar todos sus productos -ideas, valores, teorías - como los de individuos reales, concretos, históricos, 'condicionados' por su proceso de vida real en el marco de una sociedad dada. Pero entonces, ¿cómo puede ser posible en absoluto una teoría de la revolución social que, por todo su contenido, por su significado inherente y su intención inmanente, apunta a la transformación radical de estas condiciones históricas actuales? ¿Cómo conciliar el postulado teórico de un historicismo radical con la exigencia y la actitud prácticas de una trascendencia radical respecto a la etapa presente de la historia?

La respuesta de Marx a esta pregunta, en su intención más general, consiste en transformar simultáneamente el significado de 'realidad social' y de 'teoría. Una teoría de la revolución social es posible sólo si logra vincularse con la realidad del presente no sólo como objeto de análisis y explicación, sino también como sujeto, a la vez limitado-'condicionado' y activo-poiético, lo cual 'se expresa' en la caracterización dual pero unificada de un sujeto 'sufriente' y 'combatiente'. Sólo así puede la teoría "desarrollar, a partir de las formas presentes de la realidad existente, la realidad verdadera como su Deber (Sollen) y su fin último"25. La teoría crítica no pretende 'prescindir de presuposiciones', pero sus presuposiciones son 'empíricas reales': la existencia en la sociedad de 'fuerzas' subjetivas radicales de este tipo, que la teoría no 'describe' sino que las lleva a su expresión articulada; fuerzas que, por el otro lado, no 'consumen' la teoría como un producto cultural sino que reconocen en ella la articulación

25 Werke, vol. 1, p. 345 . 
de sus propias aspiraciones, que no pueden ser satisfechas bajo las condiciones de vida imperantes.

Hemos señalado, aunque sea de manera bastante abstracta, algunas de las razones por las cuales Marx ha sustituido imperceptiblemente (desde la Ideología alemana) esta comprensión de las 'condiciones de posibilidad' de su propia teoría por otra, con cantidad de "hechos que hay que establecer de manera puramente empírica”. De esta manera, el marxismo volvió a ser una teoría en el sentido clásico de la palabra, una teoría de la realidad social como proceso, en el sentido dual de una ciencia determinista de la reproducción de una estructura social particular y de una teoría finalista (valorativa sin decirlo) del progreso histórico. La 'radicalización' del marxismo, en el sentido que proponemos, significa entonces, en cierto sentido, un 'regreso a las fuentes', por lo menos si es lícito comprender así una reconstrucción hipotética de las 'intenciones originales' de Marx (entendidas como el significado objetivo de su 'ruptura' con tradiciones teóricas anteriores), una reconstrucción realizada desde el punto de vista de los problemas teóricos y las exigencias prácticas de nuestros días.

Esta 'radicalización' significa, antes que nada, que la precondición 'trascendental' de la posibilidad de la teoría crítica es la existencia, la realidad empirica 'vivida' de necesidades radicales que, en su contenido, 'trascienden' el presente y apuntan hacia una nueva organización de la sociedad y nuevas formas de vida ${ }^{26}$. La teoría ofrece a la vez una explicación y una interpretación de la realidad de estas necesidades históricas o 'condicionadas', vividas por lo menos bajo la forma de insatisfacción y angustia mudas. Las explica en la medida en que demuestra que surgen de formas actuales de las actividades vitales, de la reproducción de las 'condiciones materiales de la vida' en la

\footnotetext{
${ }^{26}$ Sobre el papel del concepto de "necesidades radicales" en la teoría crítica, véanse los escritos de Agnes Heller, esp. The Theory of Need in Marx, Londres, 1976; y "Theory and Practice from the Point of View of Human Needs", en A. Hegedüs, A. Heller, M. Márkus y M. Vajda, The Humanisation of Socialism, Londres, 1976. Hay, sin embargo, algunas diferencias entre nuestras posturas respectivas, sobre todo respecto a la cuestión de las necesidades latentes. En cuanto a las intenciones fundamentales, las ideas presentadas aquí deben mucho a los primeros escritos de Max Horkheimer.
}

'forma social' dada, a través de relaciones sociales determinadas. Las interpreta en el sentido de que la teoría muestra la imposibilidad de satisfacerlas bajo las condiciones sociales dadas, abriendo así el camino para pensar en una alternativa a la organización social presente (a la reproducción de las 'condiciones materiales'), y por lo tanto transformando el sufrimiento padecido en intenciones y aspiraciones conscientes. "La causa principal de la ira moral no es el sufrimiento objetivo: ésta es la causa social aparente. Percibir las causas como humanas es un primer paso necesario para poder hacer algo respecto a la miseria humana y a la injusticia" 27 . La explicación de las necesidades como efectos de una estructura social y su interpretación como potencialidades de transformación de ésta se unifican en la teoría en la presentación de las necesidades radicales como factores causales de las disfunciones (sentidas y eliminables) de la sociedad.

Pero las necesidades radicales no son sólo ese 'afuera' del sustento existencial al cual la teoría crítica tiene necesariamente que acudir, también condicionan el contenido conceptual de la teoría en la medida en que la distinción básica entre 'condiciones materiales' y 'relaciones sociales' sólo se puede trazar en función de ellas. Las 'condiciones materiales' son precisamente aquellos elementos de la vida social que, en relación con las necesidades formadas por la historia, representan una precondición necesaria de la vida humana, tienen el significado práctico de una objetividad no investida de valor (indiscutible). Las 'relaciones sociales' son, por lo tanto, postuladas como los mecanismos institucionales y sus 'materializaciones', mediante los cuales se regula la reproducción de dichos elementos y que pueden, en principio, ser cambiados, y que por ello tiene sentido someterlos a cuestionamientos y desafíos, en cuanto a su carácter bueno o malo, justo o injusto. La validez de la teoría crítica presupone el cumplimiento simultáneo de la pretensión teórica de ofrecer, a partir de esta distinción, un modelo 'confirmable' de reproducción de la totalidad social desde el punto de vista de sus tensiones y disfunciones estructura-

\footnotetext{
${ }^{27}$ Barrington Moore, Injustice: The Social Bases of Obedience and
} Revolt, White Plains, 1978, p. 455. 


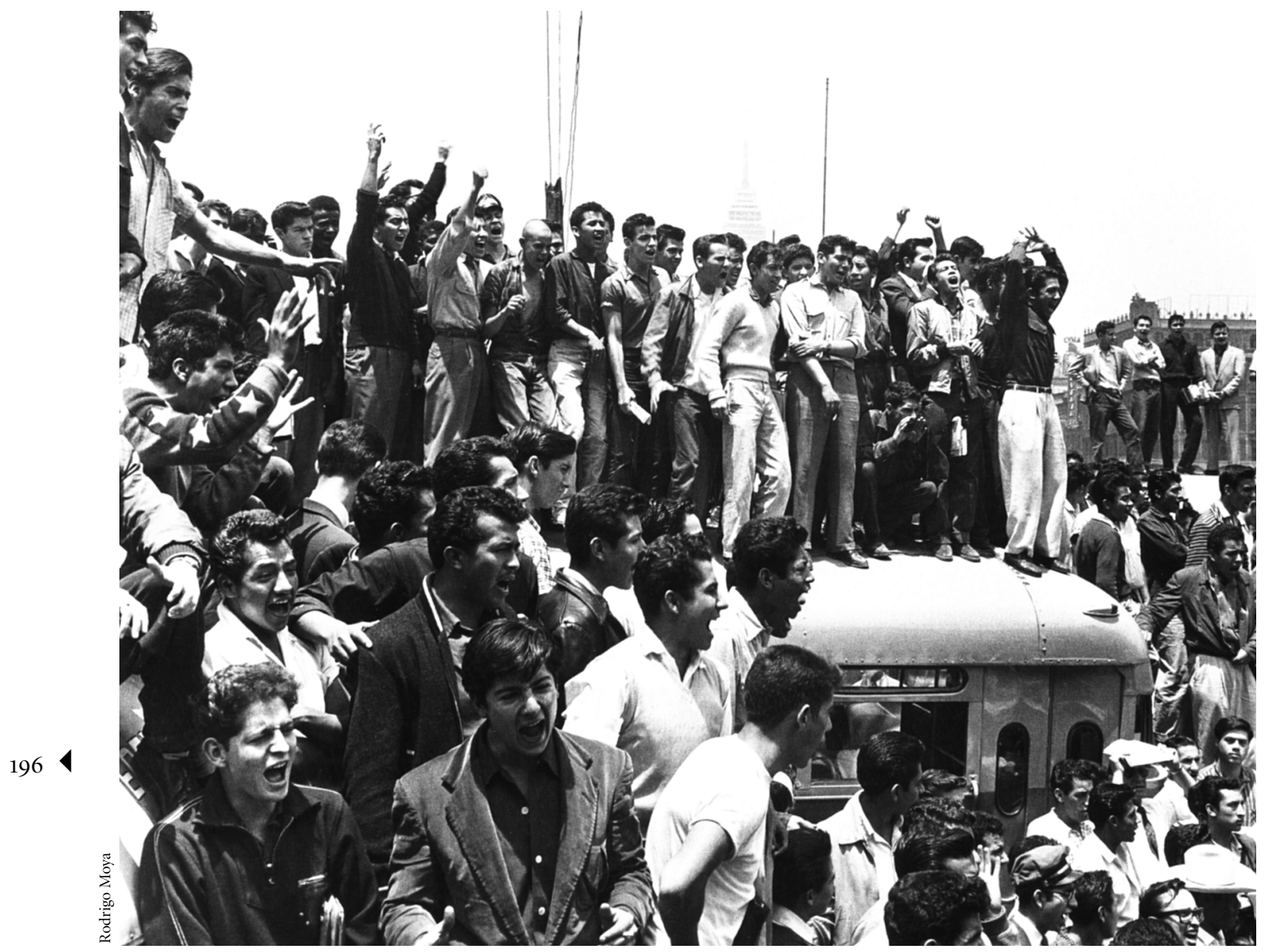

Movilizaciones magisteriales y estudiantiles. Zócalo, ciudad de México, 1958.

les, y de la pretensión práctica de apuntar a una posible alternativa de organización social tal que los sujetos a los cuales se dirige puedan reconocer en ella la expresión de sus propias aspiraciones. Y, por supuesto, el paradigma de la producción, que formula la distinción entre 'contenido material' y 'forma social' básicamente en términos de 'fuerzas productivas' y 'relaciones de producción', implica simultáneamente la presuposición práctica de que en la sociedad moderna el terreno más decisivo, tanto para la emergencia de necesidades radicales como para el resultado de las luchas sociales que determinan la posibilidad de su satisfacción, está constituido por la organización económica productiva.
Pero esta unidad metodológica de la explicación y la interpretación en la teoría crítica no implica la concurrencia necesaria de sus pretensiones teórica y práctica, no significa la disolución de la distinción fundamental entre exposición teórica como tal y autoeducación colectiva práctica. La teoría nunca puede 'demostrar' la existencia de necesidades radicales, es decir, la existencia de sujetos tales que reconozcan sus propias intenciones en la alternativa ofrecida. Las necesidades del cambio sólo se pueden demostrar, como lo formuló el propio Marx, ad hominem. La teoría no puede construir su propio sujeto, sólo puede evocarlo. No sólo está fuera de su alcance garantizar el éxito de un diálogo práctico con sus pretendidos 
sujetos, sino que tampoco puede presumir que contiene los resultados esperados de este proceso de autoeducación comunicativa. La teoría crítica puede abrir, volver imaginable, un futuro alternativo, tratando así de dar voz a la miseria muda del presente y de transformar tal miseria o frustración en aspiraciones radicales conscientes. Pero las necesidades y las aspiraciones cambian en el proceso mismo de su realización y en un diálogo auténtico, ninguno de los interlocutores sigue siendo lo que era. La pretensión de validez de la teoría es ante todo práctica, una apuesta a la continuidad y a la fecundidad del diálogo, del "proceso de aprendizaje" (como Bildung) y no a la inmutabilidad de una 'doctrina verdadera'.

La teoría crítica, como atalaya del historicismo radical de la finitud humana, debe asumirse como radicalmente histórica. Y está 'limitada' no sólo en este sentido de su 'apertura' respecto a cambios futuros de contenido, sino también en el sentido de su 'cerrazón' en cuanto al presente. Al analizar el presente desde el punto de vista de una alternativa social futura basada en la interpretación de necesidades radicales definidas, tiene que pensar y probar esta perspectiva práctico-histórica bajo el postulado de su posibilidad de universalización, de su capacidad de conducir la unificación práctica del género humano. Pero mientras esta unidad no pase de ser una idea reguladora, mientras relaciones de dependencia y de dominación articuladas de distintas maneras sigan siendo constitutivas a la vez dentro de una sociedad y en las relaciones entre distintas sociedades, no puede existir garantía, por lo menos a priori, de la unicidad del sujeto radical, es decir, de la compatibilidad y coherencia mutuas de todas las necesidades radicales que cuestionan 'legítimamente' el sistema existente al expresar sufrimientos humanos reales y, en principio, eliminables. Bien puede ocurrir que el 'costo' de eliminar una de las fuentes de la miseria humana sea 'insoportable' para otros agentes sociales, igualmente oprimidos pero en otros aspectos, mediante mecanismos distintos de dominación ${ }^{28}$. Y si uno toma en serio la pre-

28 "Incluso si uno acepta que la tesis neomarxista sobre la disolución del proletariado revolucionario en los Estados industriales desarrollados es falsa, tiene que conceder, por lo menos, que existen, por así decirlo, varios proletariados. Para decirlo de una manera muy simplificada: suposición marxiana de que los esfuerzos por conseguir la pluridimensionalidad del individuo representan una necesidad radical en las sociedades industriales actuales, entonces la pluralidad de sujetos radicales tiene que presentarse para la teoría crítica no sólo como una posibili-

está por ejemplo el proletariado del Tercer Mundo, al que el predicado marxista de 'pauperización' caracteriza de manera adecuada, pero no el de 'portador de las fuerzas productivas'. Además, está el proletariado de la sociedad industrial occidental, al que uno puede sin duda seguir aplicando (también en un sentido económico) el predicado de 'alienación' pero no el de 'pauperización'. Y peor todavía: incluso si se pudiera atribuir un potencial revolucionario a esos dos proletariados, en ningún caso se les puede adscribir los mismos intereses materiales." (K. O. Apel, Transformation des Philosophie, vol. 2, pp. 432-433). De esta aporía, Apel deriva la conclusión de que toda participación concreta en una situación histórica práctica debe anclarse en una ética filosófica. Esta solución nos parece ilusoria. En la medida en que significa la exigencia de incluir dentro de cualquier perspectiva de emancipación la situación del 'Otro', es decir, el postulado de universalibilidad en principio, formula indudablemente uno de los requisitos más vitales para toda teoría radical. Pero eso no elimina la diversidad o la incompatibilidad iniciales de las situaciones prácticas, sólo las hace explícitas (y materia, por lo tanto, de un posible diálogo). Nada impide que, desde la situación vital de alguno de los sujetos radicales potenciales, parezca deseable una forma de vida que se pueda, en principio, volver universal, pero que no sea deseada (no constituya una 'buena vida') desde el punto de vista práctico de otros agentes posibles del cambio radical. Incluso suponiendo (sin conceder) que la reflexión filosófica sobre las precondiciones trascendentales de la comunicación pudiera desembocar en un ideal de sociedad válido para todos y en todo tiempo, las normas así definidas no podrían cumplir la función de 'estándares' o 'criterios' para formular un juicio orientador del valor histórico relativo de proyectos de emancipación diversos. En el caso de conflictos reales de necesidades, las normas continuarían siendo, contra sus exigencias vitales, postulados abstractos y, por la otra, principios formales inservibles para evaluar cualquier proyecto emancipatorio, ya que la impredecibilidad de la historia impide decir cuál de ellos podría servir realmente para 'aproximar' el ideal. No se puede superar la antinomia refiriéndose a una ética inamovible de igualdad de los discursos, es decir, por puros medios intelectuales. Se puede resolver (si acaso) sólo en la práctica, en el diálogo (Gespräch) real de diversas perspectivas, en el cual los propios participantes (es decir, sus necesidades) se vayan cambiando y que vayan formando su propia ética en el camino, ética fundada no en una igualdad e identidad abstractas, sino en la solidaridad dentro de las diferencias y a pesar de los antagonismos. Naturalmente, tal diálogo no se puede dar si no existe un consenso antecedente mínimo de experiencias e interpretaciones compartidas. Saber si el género humano - a pesar de todos los antagonismos sociales, nacionales y culturales - representa ahora una unidad 'en sí, en el sentido de aquellas interconexiones objetivas que hacen que cada acontecimiento significativo en algún lugar del planeta tenga repercusiones en todas partes, saber si este hecho (y la posibilidad de una autodestrucción común) crea o no una base suficiente para tal diálogo sigue siendo una pregunta abierta. Aquí, la filosofía crítica sólo puede formular un recordatorio: en nuestros tiempos, o la humanidad es una o puede ser ninguna. 
dad empírica (que constituye una enorme dificultad para cualquier proyecto de emancipación), sino también como un postulado confirmado. Si la pluralidad de valores, imposibles de ordenar en una jerarquía fija y que ofrece la posibilidad de elegir entre varios tipos de formas de vida, se plantea como valiosa en sí misma, entonces la unidad del género humano ya no se puede pensar ni bajo la categoría de un sujeto (encarnado en el presente en el agente único de transformación radical) ni bajo la noción de un consenso alcanzado (que una teoría única pudiera prefigurar en abstracto). Por el contrario, tal unidad se tendría que entender como el proceso continuo de un diálogo ininterrumpido, basado en la solidaridad práctica y la tolerancia creativa, entre diferentes culturas y formas de vida. La teoría crítica que articule esta perspectiva no puede asumirse como la teoría de la emancipación; para ella, la pluralidad de teorías radicales no es un lamentable hecho empírico que habría que superar sino una precondición de emancipación (puesto que es la articulación de intereses emancipatorios' diversos) — si es que un diálogo de solidaridad entre distintos puntos de vista puede advenir.

En todos estos aspectos, la teoría crítica se encuentra en una situación que no es la superación sino más bien la realización abierta de las antinomias de la filosofía. Comparte con la filosofía clásica la pretensión de ser sólo la autorreflexión (como Selbstdenken y Selbtbesinnung) de su sujeto, junto con la conciencia de que es imposible obligar a nadie a filosofar. Comparte con la filosofía la obligación de pensar su propio contenido bajo el postulado de la posibilidad de universalización, junto con el reconocimiento de la pluralidad irreductible y no superable de puntos de vista filosóficos válidos.

En nuestra época, cuando el fin de la filosofía, de la metafísica, del humanismo, etc., se ha convertido en un lugar común, el programa marxiano de abolición de la filosofía mediante su realización ha cobrado, como bien lo señaló Adorno, un sentido más bien ominoso. La filosofía empieza cuando vacila aquella mítica visión del mundo en la cual "el ethos de un grupo es presentado como intelectualmente razonable al mostrar que representa un modo de vida idealmente adaptado al estado actual de las cosas descrito por esta visión del mundo, mientras dicha visión del mundo se vuelve emocionalmente convincen- te al ser presentada como una imagen del estado actual de cosas particularmente bien pensada para adaptarse a tal modo de vida"29. La filosofía empieza cuando esta síntesis inmediata se derrumba, cuando se empieza a distinguir entre physis y nomos y su relación se convierte en un problema. Su historia es la historia de intentos constantes tanto para reformular esta distinción como para construir una relación entre los conceptos así distinguidos. $\mathrm{Su}$ 'fin' acontece cuando se deja de considerar que las relaciones entre naturaleza y convenciones, objetos y valores, hechos y normas, ciencia y moral, etc., etc., constituyen un problema significativo.

En este sentido, dos grandes tendencias intelectuales del presente pueden legítimamente proclamar que ponen fin a la filosofía. Por un lado, el positivismo considera el asunto como un pseudoproblema, ya que nunca se puede derivar el 'debe' del 'es' y por lo tanto las normas nunca pueden ser 'verdaderas' en el sentido estricto de la palabra. La elección de valores es, por lo tanto, asunto de decisiones y compromisos 'irracionales', y la justificación de las normas una empresa sin sentido. La racionalidad sólo se refiere al conocimiento de los hechos, es decir, a la elección de medios adecuados para fines dados; la razón es instrumental por naturaleza y la filosofía sólo puede sobrevivir como la ciencia de los hechos de las ciencias. Por el otro lado, algunas 'filosofías de la comunicación' igualmente insisten en la ausencia de un problema real, ya que la distinción entre hechos y normas en su generalidad filosófica es simplemente imposible de trazar. Los 'hechos' se pueden identificar y expresar dentro de algún sistema de reglas y normas de comunicación, y las reglas del lenguaje (en el sentido amplio) no son convenciones arbitrarias sino hechos de la vida. La justificación (y la crítica) de reglas y normas específicas (lo mismo que la explicación de hechos) sólo es posible dentro del marco de una forma de vida determinada ('cultura,' 'tradición', 'juego de lenguaje'), constituida por hombres que en determinadas situaciones actúan conforme a determinadas reglas, forma de vida en la que cada uno de los términos involu-

${ }^{29}$ Clifford Geertz, "Religion as a Cultural System", en Anthropological Approaches to the Study of Religion, Londres, 1966, p. 3. 
crados — situación, acción, reglas— - sólo se puede definir en relación con los demás. Pero una forma de vida no puede tener más justificación que la de ser la tradición que nos es dada, que nos habilita —al participar en ellapara actuar y juzgar racionalmente. La ciencia misma es una actividad regida por normas definidas que pertenecen a una cultura y a una forma de vida definidas. La filosofía sólo puede sobrevivir si abandona su pretensión de ser una 'teoría', de dar respuestas generales a los supuestos problemas de hechos y normas. Sólo se puede asumir como actividad pura que siempre nos recuerda algo que ya 'conocemos' en la práctica de la vida —el entretejimiento indisoluble de los 'hechos' y las 'reglas' como fundamento insuperable e incuestionable de la racionalidad humana. La filosofía sólo debería ofrecer una profilaxis contra las pretensiones exorbitantes e ilegítimas de la razón (formuladas primero en la misma filosofía clásica), un recordatorio constante de sus límites y de su finitud.

“... desarrollar, a partir de las formas presentes de la realidad existente, la realidad verdadera como su Deber y su fin último": esta ya citada declaración programática temprana de Marx suena, sin duda, en el contexto de las discusiones filosóficas actuales no como la abolición sino más bien como la reafirmación de la pretensión tradicional de la filosofía. Y, aunque evitó más tarde toda formulación que mencionara 'deberes' y 'fines', no es difícil ver que el 'paradigma de la producción', el núcleo teórico de su pensamiento tardío, contiene otra reformulación más de la antigua distinción entre physis y tesis ${ }^{30}$. 'Contenido material' y 'forma social', estos dos conceptos que expresan respectivamente las relaciones del hombre

30 'Reformulación' aquí significa: una articulación y afirmación de esta distinción tal que, en su marco, sea posible dar respuesta a todo el complejo de problemas que, en la filosofía tradicional, se ha aglutinado en torno a esta distinción. No significa, definitivamente, reducir todas las distinciones conceptuales diversas elaboradas en la filosofía tradicional a una única distinción entre 'contenido material' y 'forma social' ('técnico' versus'social'). Si el paradigma de la producción (aun en su forma 'revisada') es capaz de cumplir con esta exigencia no fue una pregunta investigada en toda su extensión en el presente trabajo. No se discutió para nada lo que, para muchos, es su aspecto más cuestionable: su aplicabilidad al terreno de la vida cultural. La razón de eso es, naturalmente, que en mi perspectiva el paradigma de la producción en su formulación marxiana original ya es problemático en su aplicación a la vida 'material'. con la naturaleza y las relaciones entre hombres como opuestos son una conceptualización más ofrecida para trazar la línea entre lo que sólo puede ser averiguado y tomado en cuenta, explicado en cuanto a sus causas y utilizado, por un lado; y por el otro, lo que, en principio, puede ser objeto de decisión, cuyas razones pueden justificarse o criticarse, y que se puede defender o derribar.

$\mathrm{Al}$ articular esta distinción dentro del 'paradigma de la producción', Marx propone una solución al problema filosófico relativo a 'naturaleza' y 'convención', 'hechos' y 'normas', una solución que trasciende, en cierto sentido, la 'uniteralidad' tanto de las 'filosofías de la comunicación' como del positivismo. Por un lado, el paradigma de la producción insiste en la unidad indisoluble de hechos y reglas en la constitución misma del mundo vital como realidad material humana. Y no sólo en el sentido de que cada objeto hecho por el ser humano o, en términos más generales, cada elemento humanamente significativo del entorno del hombre es simultáneamente una objetivación de relaciones pasivas y activas específicas del hombre con la naturaleza (necesidades y capacidades específicas) y una materialización, un 'portador' de formas sociales definidas, sino también porque las nociones de objetivación y de materialización presuponen, ambas, la noción de reglas sociales. La distinción que tiene sentido hacer no se establece entre hechos desnudos y reglas desencarnadas derivadas de convenciones, sino entre dos elementos, dos constituyentes de la factualidad social, ambos co-constituidos mediante reglas, pero de distinto tipo: reglas 'técnicas' y reglas, en sentido estricto, 'sociales'. Pero esta distinción es siempre relativa al momento histórico, en el fondo a la situación vital de los sujetos sociales que la trazan. Lo que desde un punto de vista sociohistórico definido sería un simple hecho o una necesidad técnica puede ser visto, desde otra perspectiva, como expresión y afirmación de una elección específica de valores o de intereses particulares. Lo que podemos llamar la 'crítica de las ideologías', en el sentido amplio de la palabra (que incluye el caso más trivial en el cual, 'por detrás' de la motivación explícita de alguien, uno ve sus causas), siempre implica un intento de trazar la línea que separa 'hechos' de 'normas', lo 'técnico' de lo 'social', de manera distinta a como el sujeto lo hace o lo hizo. Cuando el antropólo- 
go explica alguna representación religiosa (que remite para los 'nativos' a una entidad existente que forma parte del andamiaje ontológico del mundo) como mera expresión de las relaciones formales que se dan entre unas personas y sus grupos sociales en la sociedad considerada, él (o ella) en realidad está transformando 'hechos' en 'normas.'Y cuando explica un conjunto particular de prescripciones religiosas en términos, digamos, de su utilidad o necesidad funcional dentro del ecosistema dado, está realizando la transformación inversa, haciendo 'hechos' a partir de 'normas'.

Pero al mismo tiempo es preciso hacer la distinción mencionada, y hacerla en el sentido de contraponer las exigencias y necesidades de la naturaleza a la esfera en la cual se pueden dar, principalmente, elecciones humanas. La acción racional sólo es posible si uno puede distinguir, por un lado, entre sus condiciones y los medios disponibles que se han de tomar en cuenta y utilizar; y por el otro, los objetivos y fines que han de elegirse y tratar de alcanzar. Cuando la actividad social deja de ser dirigida por la tradición, cuando su carácter poiético se vuelve un problema consciente, surge entonces la tarea de establecer esta distinción de manera sistemática, general y justificada. Llega entonces el tiempo de la filosofía. Pero una vez que eso está hecho, que las esferas del physis y el nomos quedan diferenciadas básicamente (bajo cualquier forma de conceptualización) no hay manera de encontrar una conexión lógica válida entre las dos. No sólo es imposible deducir 'debe' de 'es', sino que tampoco se puede inferir de un 'contenido material' dado su 'forma social', aunque, por supuesto, una totalidad particular de valores de uso no puede ser producida por mecanismos de regulación social arbitrarios. Pero cualquier 'explicación' de la génesis de tales mecanismos es por necesidad histórica, en el sentido estricto de la palabra, es decir, que tiene que referirse no sólo a una constelación única de 'circunstancias' sino a circunstancias interpretadas por los propios actores sociales a la luz de sus necesidades, intenciones e intereses.

Ahora bien, ni el uso óptimo de los recursos disponibles para fines arbitrariamente dados, ni una jerarquía fija de fines, proporcionan criterios de racionalidad para la actividad de cambio radical, es decir, para la actividad que pone en tela de juicio los móviles dominantes y los propósitos socialmente sancionados de la acción humana, y no lo hace en nombre del regreso a alguna tradición previa sino por abrir el camino a la actividad creadora de valores de los individuos. La actividad poiética sólo puede ser racional si es posible encontrar algún nexo válido entre hechos y normas, medios y fines. En este sentido, el marxismo es un intento -que sigue los esfuerzos del idealismo alemán clásico - de articular una nueva idea de 'razón', que define la racionalidad como una categoría de la vida, de una praxis social mediante la cual los hombres pueden hacer una conexión consciente entre medios y fines. Si los individuos sociales, en conocimiento de las exigencias y limitaciones de su situación vital, a través de la articulación y de la confrontación dialógica de sus propias necesidades, determinan ellos mismos de manera solidaria los propósitos sociales y los valores de sus propias actividades, entonces su vida es racional. La teoría crítica de la sociedad analiza aquellas condiciones sociales que, en el presente, hacen sistemáticamente imposible la realización de esta racionalidad práctico-social. También intenta así participar - a través de esta 'interpretación' de necesidades radicales latentes - en aquel proceso de aprendizaje colectivo gracias al cual los individuos actuales pueden relacionar conscientemente los hechos de su vida con las normas de su actividad social. En este sentido, la teoría crítica ofrece una respuesta al problema sempiterno de la filosofía, al señalar que las antinomias que ella engendra no se pueden resolver en la esfera del pensamiento puro, sino sólo en la práctica social. Pero la teoría sólo puede ofrecer esta 'respuesta' bajo la forma de un proyecto de reorganización social radical que expresa la necesidad y potencialidad de la etapa histórica actual. En este sentido, sigue siendo 'meramente' una filosofía. No resuelve el 'enigma de la historia' porque, según su propio entender, no existe detrás de la historia ningún sentido oculto que pudiera ser descubierto; sólo se propone articular las condiciones bajo las cuales la vida histórica puede ser transformada ahora en una tarea válida, a la medida de los seres humanos. Pero sólo puede 'evocar' a los sujetos capaces de emprender tal tarea y dispuestos a llevarla a cabo. Que la tarea sea o no emprendida en la realidad no será un juicio sobre la humanidad, sino sobre la 'verdad' y la 'justeza' de la teoría. 